\title{
Slag Formation during Reduction of Iron Oxide Using Hydrogen Plasma Smelting Reduction
}

\author{
Masab Naseri Seftejani ${ }^{1, *} \mathbb{E}$, Johannes Schenk ${ }^{1,2} \mathbb{C}^{-}$, Daniel Spreitzer ${ }^{1}$ and \\ Michael Andreas Zarl ${ }^{1}$ \\ 1 Department of Metallurgy, Montanuniversitaet Leoben, 8700 Leoben, Austria; \\ Johannes.Schenk@unileoben.ac.at (J.S.); Daniel.Spreitzer@unileoben.ac.at (D.S.); \\ Michael-Andreas.Zarl@unileoben.ac.at (M.A.Z.) \\ 2 K1-MET GmbH, Stahlstraße 14, A-4020 Linz, Austria \\ * Correspondence: naseri.masab@outlook.com
}

Received: 27 January 2020; Accepted: 15 February 2020; Published: 20 February 2020

\begin{abstract}
Replacing carbon by hydrogen is a huge step towards reducing $\mathrm{CO}_{2}$ emissions in the ironand steel-making industry. The reduction of iron oxides using hydrogen plasma smelting reduction as an alternative to conventional steel-making routes has been studied at Montanuniversitaet Leoben, Austria. The aim of this work was to study the slag formation during the reduction process and the reduction behaviour of iron oxides. Furthermore the reduction behaviour of iron ore during continuous feeding was assessed. Mixtures of iron ore and calcined lime with a basicity of $0,0.8,1.6,2.3$, and 2.9 were melted and reduced by hydrogen. The off-gas composition was measured during the operations to calculate the process parameters. The reduction parameters, namely the degree of reduction, degree of hydrogen utilisation, produced iron, and slag, are presented. The results of the batch-charged experiments showed that at the beginning of the reduction process, the degree of hydrogen utilisation was high, and then, it decreased over the operation time. In contrast, during the continuous-feeding experiment, the degree of hydrogen utilisation could be kept approximately constant. The highest degrees of reduction and hydrogen utilisation were obtained upon the application of a slag with a basicity of 2.3. The experiment showed that upon the continuous feeding of iron ore, the best conditions for the reduction process using hydrogen could be applied.
\end{abstract}

Keywords: slag; basicity; hydrogen plasma; smelting reduction; iron oxide; plasma arc; hydrogen utilisation; degree of reduction; hematite

\section{Introduction}

Hydrogen plasma smelting reduction (HPSR) was introduced at the Chair of Ferrous Metallurgy of the Montanuniversitaet Leoben in 1992. At the beginning, HPSR was part of the Ultra Low $\mathrm{CO}_{2}$ Steelmaking (ULCOS) programme. ULCOS was a European Union programme to find innovative solutions to reduce $\mathrm{CO}_{2}$ emissions in the steel industry. However, currently, HPSR is studied within the framework of the SuSteel project in Austria.

$\mathrm{CO}_{2}$ emissions have serious consequences on the environment. $\mathrm{CO}_{2}$ emissions comprise $65 \%$ of total greenhouse gas emissions [1]. The industry sector produced approximately $15.4 \mathrm{Gt}$ of $\mathrm{CO}_{2}$-equivalent and $13.14 \mathrm{Gt}$ of $\mathrm{CO}_{2}$ in 2010 [2]. $\mathrm{CO}_{2}$-equivalent is the conversion factor of greenhouse gases in terms of the warming potential relative to that of carbon dioxide. The iron and steel industry is responsible for $4 \%-7 \%$ [3] of the total greenhouse gases. The production of 1 ton of steel generated 1.83 tons of $\mathrm{CO}_{2}$ on average in 2017 [4].

Liesienko et al. [5] characterised various iron- and steel-making processes according to their $\mathrm{CO}_{2}$ emission. The integrated $\mathrm{Hyl} 3$ Energiron electric arc furnace process route generates $1171 \mathrm{~kg}$ of $\mathrm{CO}_{2}$ 
emissions per ton of steel, which is the minimum among all the steel-making processes. Figure 1 shows the different iron- and steel-making process routes with their optimal amount of $\mathrm{CO}_{2}$ emissions $[6,7]$.

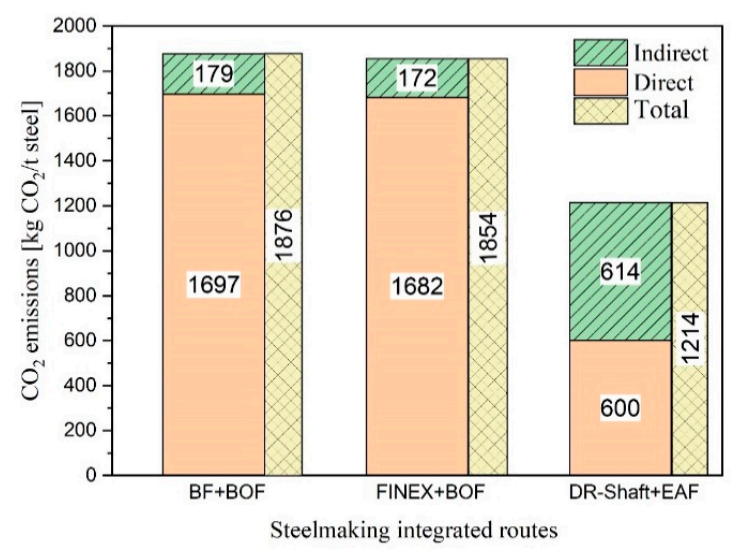

Figure 1. $\mathrm{CO}_{2}$ emission intensity of integrated steel-making processes [6,7].

$\mathrm{CO}_{2}$ emissions can be divided into two types: direct and indirect emissions. The former are emissions which occur directly at the production site, whereas the latter are the emissions from raw material transportation and the production of electrical energy and oxygen. For the conversion of the electrical energy production into $\mathrm{CO}_{2}$ emissions in the DR-shaft-EAF route, $1 \mathrm{kWh}$ of energy is considered to be equal to $0.6 \mathrm{~kg}$ of $\mathrm{CO}_{2}$.

The integrated blast furnace-basic oxygen furnace route accounts for $71 \%$ of the total steel production, translating into $1876 \mathrm{~kg}$ of $\mathrm{CO}_{2} /$ ton of liquid steel [7]. Compared with this, the integrated direct reduction shaft-electric arc furnace process generates less $\mathrm{CO}_{2}$ emissions. Therefore, the use of hydrogen as a reducing agent for $\mathrm{CO}_{2}$-free steel-making could be an appropriate alternative process $[8,9]$.

With respect to the hydrogen species in the plasma state, they can exist as molecular $\mathrm{H}_{2}$, atomic $\mathrm{H}_{\text {, }}$ ionic $\mathrm{H}^{+}, \mathrm{H}_{2}^{+}, \mathrm{H}_{3}^{+}$, and exited $\mathrm{H}^{*}$ states. At ambient temperature, hydrogen is stable in its molecular $\mathrm{H}_{2}$ form. According to the Saha equation, hydrogen molecules start to dissociate at temperatures above $3000 \mathrm{~K}$. The dissociation and ionisation of hydrogen atoms are two separate processes. At high densities and temperatures, hydrogen is ionised easily [10-12]. Hydrogen particles in the plasma state are strong reducing agents for iron oxides [13]. In the HPSR process, hydrogen in the plasma arc zone can be activated to be used for the reduction of iron oxides.

One of the main advantages of using HPSR is its ability to produce steel from iron ore powders without pre-agglomeration by using only a single-process step [14]. Numerous investigations have been carried out to produce metal from its ores by using hydrogen plasma [15-22]. They studied the reduction behaviour and the relevant parameters during the reduction of oxides using hydrogen in plasma state. The reduction of iron ore with hydrogen in a DC plasma jet was studied by Gilles and Clump [23]. They used a DC plasma jet with a water-cooled plasma torch to generate an arc for the smelting process. Iron ore powder with two different grain size distributions, 63-74 and 44-53 $\mu \mathrm{m}$, was used to carry out the experiments. The iron ore powder was fed continuously to a water-cooled copper crucible in the reduction zone and was reduced using a flow of pure hydrogen or a mixture of argon and hydrogen in the plasma arc zone. They reported that the degree of reduction is decreased by an increase in the iron ore particle size. Moreover, the degree of reduction increases upon an increase in the plasma energy and the plasma temperature. Therefore, the heat transfer to oxide particles is the limiting kinetic factor for the reduction process.

The reduction behaviour during HPSR has been investigated by some researchers at Montanuniversitaet Leoben [15,24-27]. Badr et al. [8] studied the main parameters influencing the reduction behaviour of different iron ores in the HPSR process. One of the main results was a lower degree of hydrogen utilisation $\left(\eta_{\mathrm{H}_{2}}\right)$ when using a high concentration of hydrogen in the mixture of 
$\mathrm{H}_{2}$-Ar. Their results were in good agreement with the observations of other researchers [28-32]. In the present study, the concentration of hydrogen in the gas mixture was set to be constant.

The temperature and the basicity of the slag are parameters which influence the reduction behaviour, because partial solidification limits the transport of oxygen to the reduction interface. $\mathrm{Badr}$ [15] studied the ternary slag systems $\mathrm{Al}_{2} \mathrm{O}_{3}-\mathrm{SiO}_{2}-\mathrm{FeO}$ with the addition of 0,10 , and $20 \mathrm{wt} . \% \mathrm{CaO}$. $\mathrm{He}$ reported that the slag of Carajas ore with an $\mathrm{FeO}$ content of $30 \mathrm{wt} . \%, \mathrm{Al}_{2} \mathrm{O}_{3}$ at $40 \mathrm{wt} . \%$, and $0 \mathrm{wt} . \%$ $\mathrm{CaO}$, at the temperature of $1500{ }^{\circ} \mathrm{C}$, solidifies during the process. However, with an increase in the $\mathrm{CaO}$ content to $20 \mathrm{wt} . \%$ and at the basicity of 1 , the slag is in the liquid state, which enables a $98 \%$ degree of reduction. An increase in the $\mathrm{CaO}$ content in the slag leads to an increase in the slag amount and the energy demand. Moreover, acidic slags decrease the lifetime of the refractories. Therefore, it was suggested that the process be operated at temperatures above $1600{ }^{\circ} \mathrm{C}$ and at a lower basicity. He also conducted some experiments with a basicity of $0.06,1,1.5,2$, and 2.5 to assess the effect of basicity on the dephosphorisation behaviour in the HPSR process. He reported that in the case of a higher basicity $\left(\mathrm{B}_{2}: 1.5,2\right.$, and 2.5$)$, the phosphorous level decreased.

\section{Materials and Methods}

Although the equipment, materials, and methodology of the experiments were described in detail in the previous work [33], in this section, the main points, the new methods, and experiments are briefly described.

\subsection{HPSR Laboratory Equipment}

Figure 2 shows the process flow sheet of the hydrogen thermal plasma facilities in the laboratory of the Chair of Ferrous Metallurgy at Montanuniversitaet Leoben (Leoben, Austria), including the laboratory plant and the detailed reactor layout.

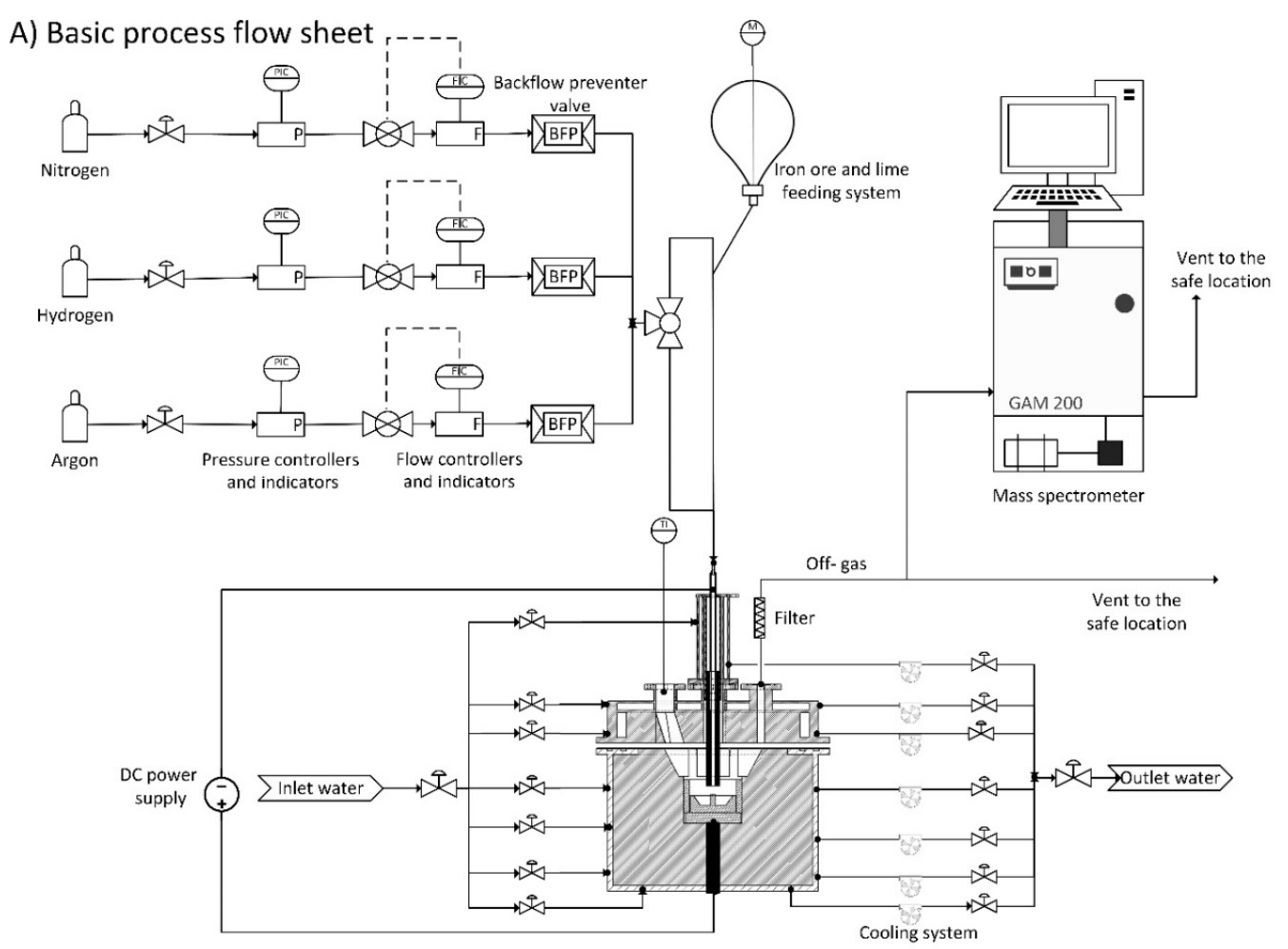

Figure 2. Cont. 


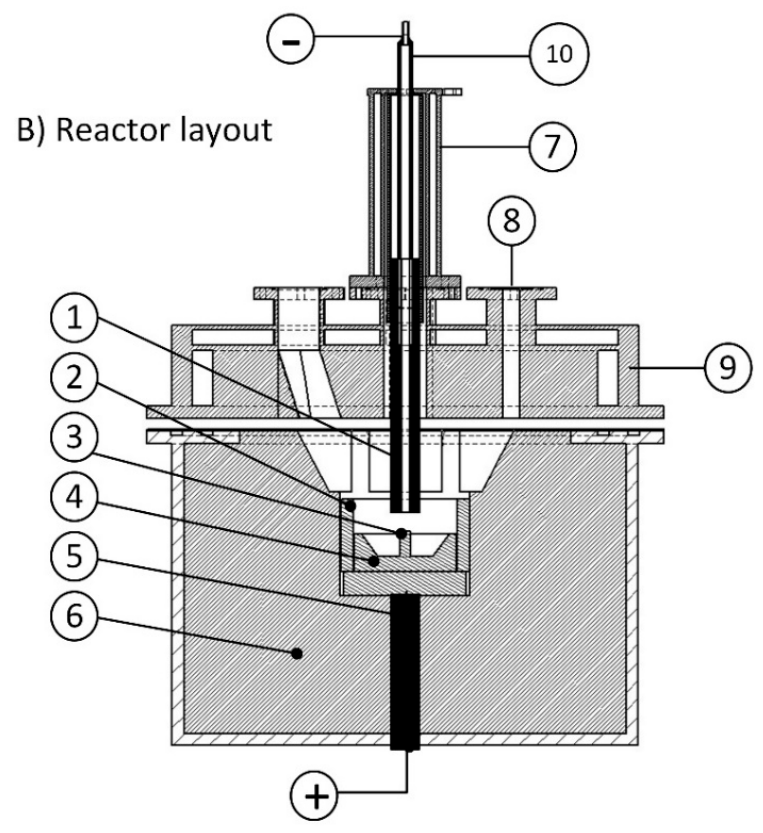

Figure 2. Process flow sheet of laboratory equipment: A) process flow diagram and B) reactor layout, reproduced from Reference [13] with permission. 1. Hollow graphite electrode (HGE); 2. Steel ring; 3. Ignition pin; 4. Steel crucible; 5 . Bottom electrode; 6 . Refractories; 7 . Electrode holder with cooling system; 8. Four orifices to (a) install off-gas duct, (b) monitor the arc, (c) install a pressure gauge, and (d) install a lateral hydrogen lance; 9. Reactor roof with refractories and cooling cooper pipes; 10. Steel pipe to inject gases and continuous feeding of fine ores.

A DC electrical power supply with the maximum power of $12 \mathrm{~kW}(20-100 \mathrm{~V}$ and $80-150 \mathrm{~A})$ was used to generate an arc between a hollow graphite electrode (inner diameter: 5-8 mm and outer diameter: $26 \mathrm{~mm}$ ) and an ignition pin. The ignition pin with a diameter of $10 \mathrm{~mm}$ was welded at the centre of the steel crucible with a maximum capacity of $100 \mathrm{~g}$ of iron ore. A mixture of argon and hydrogen was injected through the hollow graphite electrode (HGE) during the operation to produce the ionised particles in the plasma arc zone. In a series of experiments, a premixed iron ore and lime was charged into a steel crucible before the run of experiments. The steel crucible was located inside a steel ring. Its inner side was covered by a refractory lining to protect the inner ring wall from the heat of the arc radiation.

To conduct another experiment for this research work, a solid powder feeding system was used to feed the premixed iron ore and lime continuously into the plasma arc zone during the arc operation. Figure 3 shows the Hi-Doser $1 \mathrm{~L}$ powder dosing instrument produced by Lambda Laboratory Instruments (Brno, Czech Republic).

The powder dispenser consists of a dosing unit and a powder distributor coupled to a stepping motor to control the number of turns per minute and accordingly the dispensing rate.

A mass spectrometer (MS), GAM 200 (InProcess Instruments Gesellschaft für Prozessanalytik $\mathrm{mbH}$, Bremen, Germany), was used to analyse the chemical composition of the off-gas. However, water vapour and dust were removed from the off-gas in the off-gas cleaning system before the off-gas entered the MS.

The optical emission spectrometer of the type Spectrolab (SPECTRO Analytical Instruments $\mathrm{GmbH}$, Kleve, Germany) was used for the chemical analysis of the steel crucible, ignition pin, and the produced iron. Moreover, the optical microscope Nikon MM 40 (Nikon Corporation, Shinagawa, Tokyo,) with the image analysis software CLEMEX Vision 7 (CLEMEX, Longueuil, Quebec, J4G 1T5, Canada) was used for the study of the microstructure of the produced iron and to define the melted section of the crucible during smelting reduction. The FEI Quanta 200 Mk2 scanning electron 
microscope (SEM) equipped with an EDX device (Thermo Fisher Scientific, Waltham, Massachusetts, U.S.)) in the low vacuum mode was used to study the topographical and chemical analyses of the slags.

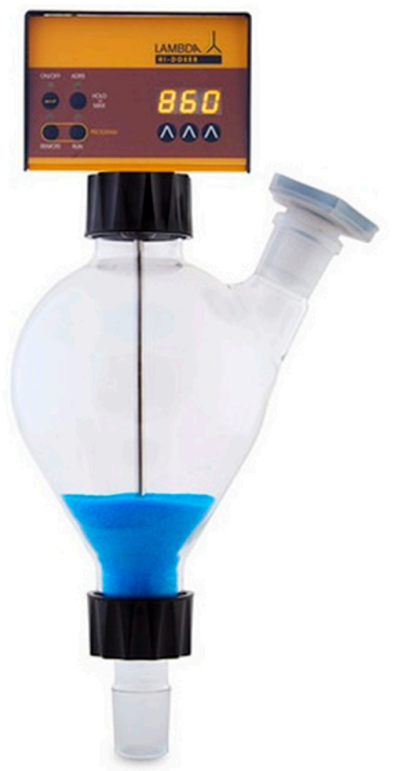

Figure 3. Hi-Doser $1 \mathrm{~L}$, powder dosing instrument.

\subsection{Experimental Programme and Materials}

In the present study, two series of experiments were designed to study the slag formation and reduction behaviour of iron ore by using the HPSR process. Table 1 shows the experimental programme for the current study.

Table 1. Experimental programme.

\begin{tabular}{|c|c|c|c|c|c|}
\hline Set of Experiments & Experiment & $\begin{array}{l}\text { Lime (g)/Iron } \\
\text { Ore (g) Ratio }\end{array}$ & $\mathrm{B}_{2}\left(\mathrm{CaO} / \mathrm{SiO}_{2}\right)$ & $\begin{array}{c}\text { Total Gas Flow Rate } \\
\text { (NL/min), } \\
1 \mathrm{~atm}, 25^{\circ} \mathrm{C}\end{array}$ & $\begin{array}{c}\mathrm{H}_{2} / \mathrm{Ar} \\
\text { Ratio } \\
(\mathrm{molar} \%)\end{array}$ \\
\hline \multirow{5}{*}{ Basicity } & Ex. 1 & $0 / 100$ & 0.0 & \multirow{6}{*}{5} & \multirow{6}{*}{$50 / 50$} \\
\hline & Ex. 2 & $1.7 / 98.3$ & 0.8 & & \\
\hline & Ex. 3 & $3.3 / 96.7$ & 1.6 & & \\
\hline & Ex. 4 & $4.9 / 95.1$ & 2.3 & & \\
\hline & Ex. 5 & $6.4 / 93.6$ & 2.9 & & \\
\hline Continuous feeding & Ex. 6 & $3.3 / 96.7$ & 1.6 & & \\
\hline
\end{tabular}

Five experiments were carried out with the basicity of $0,0.8,1.6,2.3$, and 2.9 by the addition of lime to iron ore. For instance, in Ex. 1, pure iron ore was used without any addition of lime, and $1.7 \mathrm{~g}$ of lime was added to $98.3 \mathrm{~g}$ iron ore in Ex. 2 to achieve a slag with a basicity of 0.8 . One experiment with the basicity of 1.6 was carried out with a continuous feed of the powder into the crucible to evaluate the reduction behaviour.

To run the set of basicity experiments, $100 \mathrm{~g}$ of the premixed iron ore and lime was charged to the steel crucible before running the experiments. However, for the experimental run with continuous feeding, $20 \mathrm{~g}$ of the material was charged into the crucible and $80 \mathrm{~g}$ was continuously fed during the reduction process in $1380 \mathrm{~s}$.

The flow rate of argon and hydrogen and the total flow rate for all the experiments were kept constant. The flow rate of the injected premixed argon and hydrogen was $5 \mathrm{~L} / \mathrm{min}$ with the ratio of $50 \% \mathrm{Ar}-50 \% \mathrm{H}_{2}$. As in the previous study [33], hematite iron ore from the Carajas mine (Vale S.A., 
Parauapebas-State of Pará, Brazil) was used to run the experiments with the composition listed in Table 2.

Table 2. Chemical composition of the iron ore [33].

\begin{tabular}{ccc}
\hline No. & Element & (wt.\%) \\
\hline 1 & Fe(III) oxide & 92.83 \\
2 & Fe(II) oxide & 1.07 \\
3 & Total Fe & 65.81 \\
4 & Silica & 1.694 \\
5 & Aluminium oxide & 1.01 \\
6 & Manganese (II) oxide & 0.22 \\
7 & Manganese & 0.17 \\
8 & Calcium oxide & 0.01 \\
9 & Magnesium oxide & 0.01 \\
10 & Phosphorus (V) oxide & 0.131 \\
11 & Phosphorus & 0.057 \\
12 & Sodium oxide & 0.019 \\
13 & Carbon & 0.098 \\
14 & Zinc & 0.004 \\
15 & Sulphur trioxide & 0.035 \\
16 & Total sulphur & 0.014 \\
17 & Potassium oxide & 0.017 \\
18 & LOI ${ }^{1}$ & 2.79 \\
\hline
\end{tabular}

${ }^{1}$ Loss of ignition.

The limestone was calcined at $1100{ }^{\circ} \mathrm{C}$ and then mixed with the iron ore powder. The chemical composition of the calcined lime is shown in Table 3.

Table 3. Chemical composition of the calcined lime.

\begin{tabular}{ccc}
\hline No. & Element & (wt.\%) \\
\hline 1 & $\mathrm{CaO}$ & 86.41 \\
2 & $\mathrm{SiO}_{2}$ & 4.76 \\
3 & $\mathrm{MgO}$ & 1.05 \\
4 & $\mathrm{Al}_{2} \mathrm{O}_{3}$ & 1.87 \\
5 & $\mathrm{Fe}_{2} \mathrm{O}_{3}$ & 2.50 \\
6 & $\mathrm{P}_{2} \mathrm{O}_{5}$ & 0.11 \\
7 & $\mathrm{C}$ & 0.11 \\
8 & $\mathrm{~S}$ & 0.02 \\
9 & $\mathrm{LO}$ & 3.17 \\
\hline
\end{tabular}

The grain size distributions of iron ore and lime, which were separately classified, and then were mixed, are shown in Table 4.

Table 4. Grain size distribution of Carajas iron ore and lime [33].

\begin{tabular}{ccc}
\hline Mesh Size $(\mu \mathrm{m})$ & Fraction $(w \mathrm{wt} . \%)$ & Cumulative (wt.\%) \\
\hline $63-125$ & 34 & 34 \\
$25-63$ & 60 & 94 \\
$0-25$ & 6 & 100 \\
\hline
\end{tabular}

During the experiment, the ignition pin and a part of the steel crucible were melted. The alloyed carbon from this melted steel material contributed to the reduction of iron oxides. Therefore, the compositions of these parts were important to consider in the mass balance. The chemical compositions of the steel crucible and the ignition pin are shown in Table 5. 
Table 5. Chemical composition of ignition pin and steel crucible [33].

\begin{tabular}{|c|c|c|c|c|c|c|c|c|c|c|c|}
\hline Element & Unit & C & Si & Mn & $\mathbf{P}$ & $S$ & $\mathrm{Cr}$ & Mo & $\mathrm{Ni}$ & Al & $\mathrm{Cu}$ \\
\hline Steel crucible & (wt.\%) & 0.178 & 0.261 & 1.325 & 0.009 & 0.005 & 0.083 & 0.031 & 0.168 & 0.027 & 0.179 \\
\hline Ignition pin & (wt.\%) & 0.441 & 0.217 & 0.85 & 0.008 & 0.028 & 0.985 & 0.162 & 0.085 & 0.021 & 0.116 \\
\hline
\end{tabular}

\subsection{Description of the Operation}

The set of basicity experiments were conducted using the charge of $100 \mathrm{~g}$ of premixed powder into the steel crucible. Then, the plasma reactor was assembled, and oxygen was purged out from the system by an argon stream of $5 \mathrm{~L} / \mathrm{min}$. This was done until the oxygen amount shown by the MS reached less than $1 \%$. Thereafter, the operation was started by the generation of the arc between the HGE and the ignition pin.

The first operational step was pre-melting. This was performed for $180 \mathrm{~s}$ to create a liquid pool of iron oxide. The pre-melting step was carried out under a pure argon flow at a rate of $5 \mathrm{~L} / \mathrm{min}$. The arc length at the start of the operation, which was the distance between the tip of the electrode and the ignition pin, was approximately $20 \mathrm{~mm}$. After the meltdown of the ignition pin, the arc length became approximately $35 \mathrm{~mm}$.

The next step was the reduction process, which was started by switching the gas from pure argon to a mixture of $50 \%$ argon- $50 \%$ hydrogen at a total flow rate of $5 \mathrm{~L} / \mathrm{min}$. The operation time of Ex. 3 was $25 \mathrm{~min}$. With an increase in the operation time, the transformer of the power supply got hot. Therefore, when the system was optimised, the operation time of the other experiments was extended. To achieve a high degree of reduction and to study the reduction behaviour, the operation time of three experiments was extended to $33 \mathrm{~min}$, and two other experiments were completed in $37 \mathrm{~min}$. After the arcing was stopped, the remaining hydrogen was removed from the system by purging with $5 \mathrm{~L} / \mathrm{min}$ of nitrogen for $10 \mathrm{~min}$. The chemical composition of the off-gas was recorded by using MS during operation.

For conducting the continuous feeding experiment, $20 \mathrm{~g}$ of the premixed material was charged to the steel crucible and $80 \mathrm{~g}$ was charged to the glass vessel of the powder dosing instrument to be fed continuously and uniformly during the reduction step. The process steps of this experiment are shown in Figure 4.

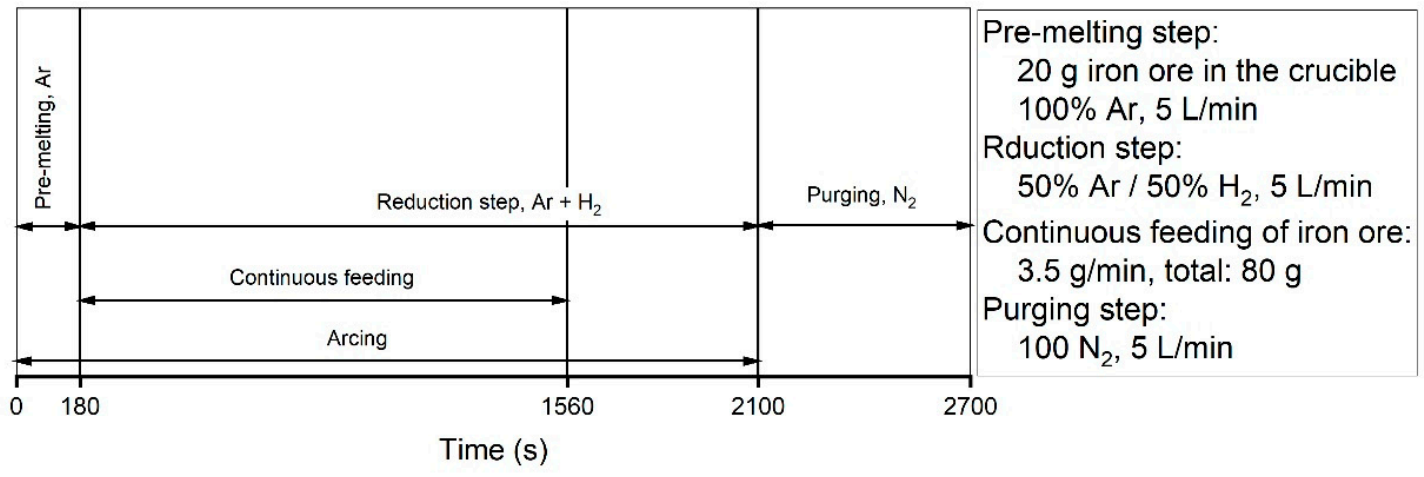

Figure 4. Process steps of Ex. 6 with the relevant parameters.

The time of the pre-melting step was $180 \mathrm{~s}$, and then, the reduction process was started with the start of the continuous feeding of the iron ore powder. The powder was continuously fed to the crucible for $1380 \mathrm{~s}$ at a feeding rate of $3.5 \mathrm{~g} / \mathrm{min}$. To compare the results of the continuous feeding experiment with those of the basicity experiments, the flow rate and the composition of the gas during the operations were the same for both series of experiments. 


\subsection{Methods}

In the pre-melting step, only argon was injected to the reactor; therefore, the outlet gas consisted of $\mathrm{Ar}, \mathrm{CO}$, and $\mathrm{CO}_{2}$. With the start of hydrogen injection to the system, the outlet gas included $\mathrm{Ar}$, $\mathrm{CO}, \mathrm{CO}_{2}, \mathrm{H}_{2}$, and $\mathrm{H}_{2} \mathrm{O}$, where $\mathrm{CO}, \mathrm{CO}_{2}$, and $\mathrm{H}_{2} \mathrm{O}$ were the reduction products. Taking a closer look inside the reactor, you need to keep in mind that the gas is not a uniform mixture, because the inserted hydrogen needs some time to be distributed uniformly, and while this is happening, hydrogen is also taking part in the reduction process. To calculate the outlet flow rate of each gas, a reference diagram was prepared with an injection of a $5-\mathrm{L} / \mathrm{min}$ flow consisting of a $50 \% \mathrm{Ar}-50 \% \mathrm{H}_{2}$ gas without arcing to a prefilled reactor with argon. Figure 5 shows the reference diagram, which illustrates the inlet and the outlet flow rate of hydrogen and argon over the time.

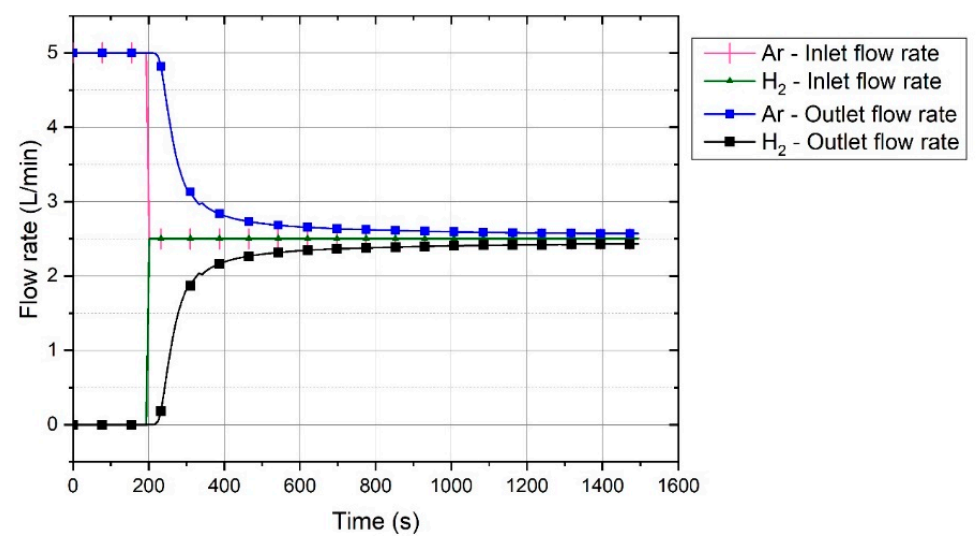

Figure 5. Reference diagram of inlet and outlet flow patterns of argon and hydrogen [33].

The flow pattern of hydrogen and argon was used as a reference diagram to calculate the flow of each gas for every experiment. The calculation procedure is explained in detail in Reference [33]. The reference diagram shows the trends of the outlet flow rate of hydrogen and argon. Upon the start of hydrogen injection, the two gases showed the set flow rate only after a period of time.

Because of the reduction reaction, a partial molar volume of hydrogen reduced iron oxides and produced water. Water vapour was condensed and separated from the gas in the off-gas cleaning system. Therefore, the amount of produced water was the difference between the amount of hydrogen shown by MS and the amount of hydrogen from the reference diagram. The hydrogen utilisation degree $\eta_{\mathrm{H}_{2}}$ was calculated as follows:

$$
\eta_{\mathrm{H}_{2}}=\frac{\% \mathrm{H}_{2} \mathrm{O}}{\left(\% \mathrm{H}_{2}+\% \mathrm{H}_{2} \mathrm{O}\right)} \times 100
$$

Iron oxide was reduced by hydrogen or carbon, when the latter was introduced from the steel crucible, ignition pin, or HGE. Therefore, not only hydrogen but also carbon contributed to the reduction reactions. The degree of reduction by hydrogen $\left(\mathrm{R}_{\mathrm{D}, \mathrm{H} 2}\right)$, that by carbon $\left(\mathrm{R}_{\mathrm{D}, \mathrm{C}}\right)$, and the total degree of reduction by hydrogen and carbon $\left(\mathrm{R}_{\mathrm{D}, \mathrm{H} 2+\mathrm{C}}\right)$ were calculated as follows:

$$
\begin{gathered}
\mathrm{R}_{\mathrm{D}, \mathrm{H}_{2}}=\mathrm{m}_{\mathrm{O}, \mathrm{H}_{2} \mathrm{O}} / \mathrm{m}_{\mathrm{O}, \text { in iron oxide }} \times 100 \\
\mathrm{R}_{\mathrm{D}, \mathrm{C}}=\left(\mathrm{m}_{\mathrm{O}, \mathrm{CO}}+\mathrm{m}_{\mathrm{O}, \mathrm{CO}_{2}}\right) / \mathrm{m}_{\mathrm{O}, \text { in iron oxide }} \times 100 \\
\mathrm{R}_{\mathrm{D}, \mathrm{H}_{2}+\mathrm{C}}=\mathrm{R}_{\mathrm{D}, \mathrm{H}_{2}}+\mathrm{R}_{\mathrm{D}, \mathrm{C}}
\end{gathered}
$$

where $\mathrm{m}_{\mathrm{O}, \mathrm{H}_{2}} \mathrm{O}, \mathrm{m}_{\mathrm{O}, \mathrm{CO}}, \mathrm{m}_{\mathrm{O}, \mathrm{CO}_{2}}$, and $\mathrm{m}_{\mathrm{O} \text {,in iron oxide }}$ are the masses of oxygen in $\mathrm{H}_{2} \mathrm{O}, \mathrm{CO}, \mathrm{CO}_{2}$, and iron oxide, respectively. Please note that all the reduction parameters were calculated using the chemical composition of the off-gas. However, to define the carbon source, a mass balance was performed. 
For the performance of the mass balance, the electrode, steel crucible, and the ignition pin were weighed before and after each test run. The weight changes of the HGE before and after the experiments showed the amount of carbon introduced into the reduction reactions. The steel crucible was partially melted during the operation, and the carbon from the crucible contributed to the reduction reactions. Therefore, to estimate the amount of carbon from the steel crucible introduced into the melt of the iron oxide, the steel crucible was cut in half, and the macro- and microstructure of the cross-section were observed with an optical microscope to estimate the amount of the melted section of the crucible. Consequently, the amount of carbon was calculated for each test run by using the partially melted section of the crucible and the carbon content of the steel.

The reduction rate by hydrogen was the rate of oxygen removed from the iron oxide upon the formation of $\mathrm{H}_{2} \mathrm{O}$. It was calculated as follows:

$$
\text { Reduction rate }=\mathrm{dm}_{\mathrm{O}, \mathrm{H} 2 \mathrm{O}}(\mathrm{g}) / \mathrm{dt}(\mathrm{min})
$$

The produced iron was obtained by the calculation of the mass balance. Accordingly, the degree of metallisation $\left(M_{D}\right)$, which is the ratio of metallic iron to total iron in iron ore, was calculated as follows:

$$
\mathrm{M}_{\mathrm{D}}=\frac{\text { Produced iron }(\mathrm{g})}{\text { Total Fe }(\mathrm{g})} \times 100
$$

Furthermore, $\mathrm{M}_{\mathrm{D}}$ was calculated as a function of the degree of reduction as follows:

$$
\mathrm{M}_{\mathrm{D}}=\frac{\mathrm{R}_{\mathrm{D}}-33.3}{66.6} \times 100
$$

\section{Results and Discussion}

Two sets of experiments were conducted to study the reduction behaviour of iron oxide and slag formation. For this purpose, the off-gas composition, produced iron, slag, $\mathrm{R}_{\mathrm{D}}, \eta_{\mathrm{H}_{2}}$, and reduction rate were studied.

\subsection{Off-Gas and Produced Iron}

Argon as an inert gas left the reactor without any reaction, and hydrogen reacted with the iron oxides, namely $\mathrm{Fe}_{2} \mathrm{O}_{3}, \mathrm{Fe}_{3} \mathrm{O}_{4}$, and $\mathrm{FeO}$, to form $\mathrm{H}_{2} \mathrm{O}$. The off-gas composition during the pre-melting step consisted of $\mathrm{Ar}, \mathrm{CO}$, and $\mathrm{CO}_{2}$, and in the reduction step, $\mathrm{H}_{2}, \mathrm{Ar}, \mathrm{CO}, \mathrm{CO}_{2}$, and $\mathrm{H}_{2} \mathrm{O}$. The produced water vapour was condensed in the off-gas cleaning system and was therefore not measured by the MS. Hence, the amount of water vapour was calculated and added to the composition graph of each test run. Every mole of hydrogen produced one mole of water; therefore, the amount of produced water vapour was the difference between the outlet hydrogen shown by MS and the reference diagram within a certain time period. The chemical compositions of the off-gas for the six experiments are shown in Figure 6.

Before starting the test runs, all the oxygen in the system was purged out by the injection of argon into the reactor. Therefore, at the start of the pre-melting step, only argon was inside the reactor. Upon the start of arcing and during the pre-melting step, $5 \mathrm{~L} / \mathrm{min}$ of argon was injected into the reactor for $180 \mathrm{~s}$. Carbon from HGE was introduced into the reduction reactions. Carbon reduced iron oxide and formed $\mathrm{CO}$ and $\mathrm{CO}_{2}$. A possible reason for the introduction of a high amount of carbon into the melt at the beginning of the process was that the HGE was cold and a thermal shock could cause a high erosion of the HGE and create a peak of $\mathrm{CO}$ and $\mathrm{CO}_{2}$ in the pre-melting step. With the formation of $\mathrm{CO}$ and $\mathrm{CO}_{2}$, the percentage of argon decreased. Then, the reduction process was carried out with an injection of a mixture containing $50 \% \mathrm{Ar}-50 \% \mathrm{H}_{2}$ at a total flow rate of $5 \mathrm{~L} / \mathrm{min}$. The trends of the gas compositions of all the experiments were similar except for Ex. 6, in which iron oxide was continuously charged into the reactor. The amount of $\mathrm{H}_{2} \mathrm{O}$ at the beginning of the experiments was 
high, and then, it decreased because of a decrease in the reduction rate. Ex. 6 had a different trend in terms of the $\mathrm{H}_{2}$ and $\mathrm{H}_{2} \mathrm{O}$ amounts, which is discussed in Section 3.2. The $\mathrm{CO}$ and $\mathrm{CO}_{2}$ produced by Ex. 6 was higher than that of the other experiments; the reasons for this are discussed at the end of this section. At 1560 s, continuous feeding was stopped, and the amount of $\mathrm{CO}$ and $\mathrm{CO}_{2}$ decreased.
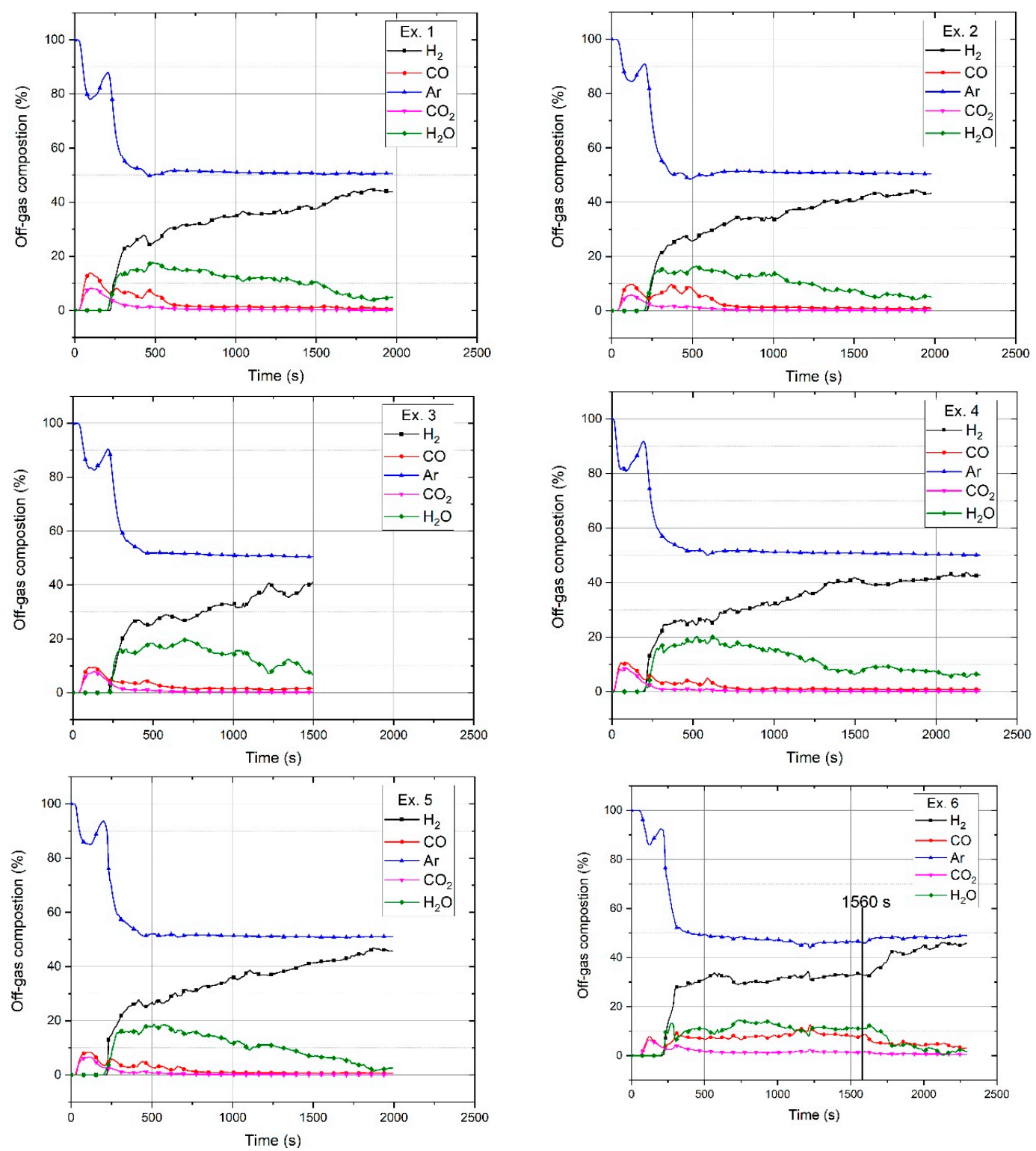

Figure 6. Chemical composition of off-gas for Exs. 1, 2, 3, 4, 5, and 6.

Ex. 3 was stopped at $1500 \mathrm{~s}$ upon reaching the temperature limit of the transformer of the power supply. To achieve a high degree of reduction and to study the reduction behaviour, the system was optimised and the operation time of Exs. 1, 2 and 5 was extended to 1980 s; Exs. 4 and 6 were carried out in $2220 \mathrm{~s}$.

Carbon contributed to the reduction processes to reduce iron oxides from three sources, namely the ignition pin, steel crucible, and HGE. During the reduction process, the ignition pin was completely melted, and the steel crucible melted partially. The partially melted section of the crucible got mixed with the produced iron and the pin material. To calculate the amount of carbon that entered into the melt from the crucible, the microstructure of the middle cross-section of the crucible was assessed using an optical microscope. Figure 7 shows a cross-section of the crucible after the reduction operation. 


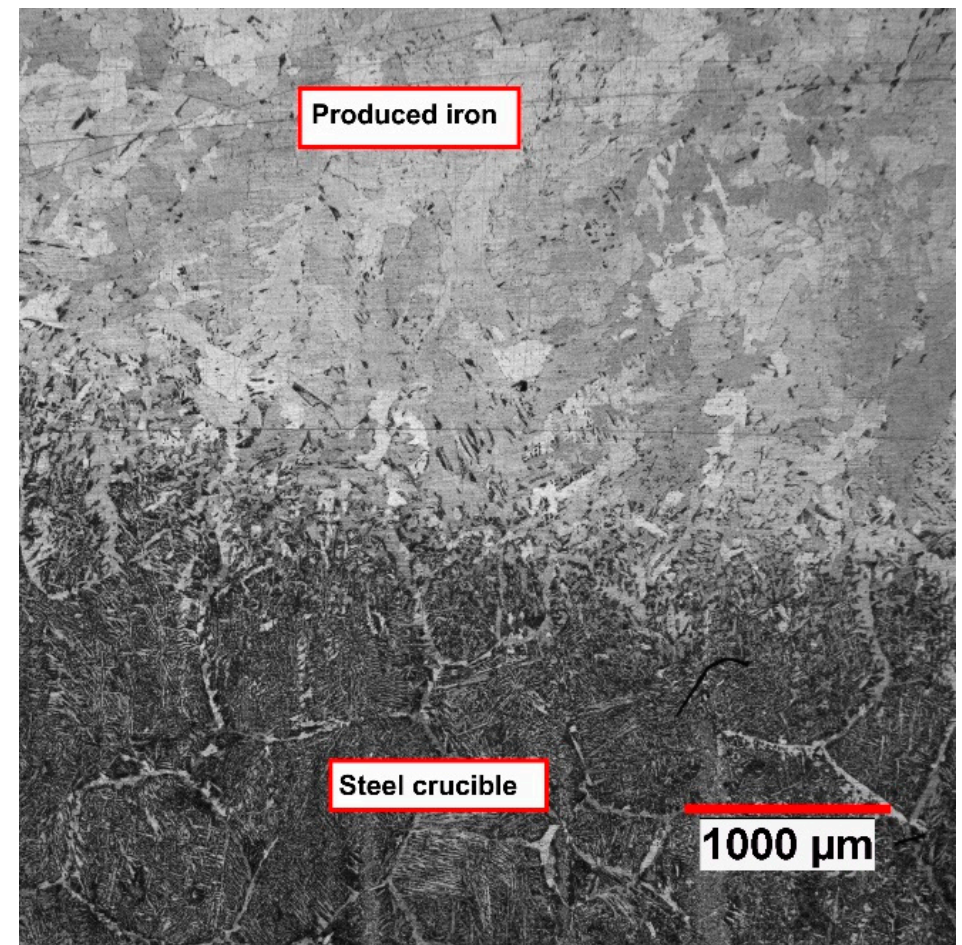

Figure 7. Cross-section of the crucible, partially melted crucible and mixed with produced iron, Ex. 3.

Figure 7 shows the weld interface and the fusion depth. The ferritic microstructure of the fusion phase illustrates a low carbon content. Nevertheless, the chemical composition of the produced iron was analysed and is presented in Table 6.

Table 6. Chemical composition of produced iron in Ex. 3.

\begin{tabular}{ccccccccccc}
\hline Element & Fe & C & Si & Mn & P & S & Cr & Mo & Ni & Cu \\
\hline $\begin{array}{c}\text { Concentration } \\
\text { (wt. } \%)\end{array}$ & 99.74 & 0.003 & $<0.001$ & 0.057 & 0.011 & 0.03 & 0.028 & 0.031 & 0.045 & 0.055 \\
\hline
\end{tabular}

The chemical composition shows that the carbon concentration is low; therefore, it means that carbon has reduced the iron oxide and formed $\mathrm{CO}$ or $\mathrm{CO}_{2}$. The melted section of the steel crucible for each test run was observed by optical microscopy, and then, the weight was estimated according to the fusion depth. Finally, the amount of carbon contributed to the reduction reactions by the steel crucible was calculated by the multiplication of the weight of the melted section and the carbon concentration. The other source of carbon was the HGE. Iron oxide fines during the continuous feeding stuck on the inner surface of the electrode and were reduced by carbon. This case was more obvious during the continuous feeding of iron ore. Moreover, the eroded particles from the HGE were introduced into the melt. Furthermore, the plasma arc caused the formation of iron oxide spatters, which stuck on the tip of the electrode and got reduced by the carbon material of the HGE.

In the pre-melting step, only argon was injected into the plasma reactor. Therefore, $\mathrm{Ar}, \mathrm{CO}$, and $\mathrm{CO}_{2}$ were the gaseous products. The amounts of produced $\mathrm{CO}$ and $\mathrm{CO}_{2}$ and their ratio were approximately in the same range for all the test runs except Ex. 6. For conducting Ex. 6, $20 \mathrm{~g}$ of the premixed powder was charged to the crucible; then, after switching the operation from the pre-melting to the reduction step, the continuous feeding of the powder was started. Therefore, the low amount of iron oxide inside the crucible led to a decrease in the $\mathrm{CO}$ and $\mathrm{CO}_{2}$ amounts at the beginning of the operation in comparison to the other experiments. However, the amounts of $\mathrm{CO}$ and $\mathrm{CO}_{2}$ emitted during the continuous feeding were higher than those of the other experiments. The possible reasons could be as follows: 
1. sticking of fines on the inner surface of HGE and the direct reduction of hematite with carbon,

2. wear of the inner section of the HGE by the inflight particles of the powder, and/or

3. generation of more slag droplets on the tip of the electrode because of entering particles of iron ore to the melt.

It is clearly shown in Figure 6 that after continuous feeding was stopped at $1560 \mathrm{~s}$, the amounts of $\mathrm{CO}$ and $\mathrm{CO}_{2}$ decreased. The total carbon in the off-gas was calculated using its chemical composition from MS. However, to define the carbon source, the mass balance of the HGE, ignition pin, and steel crucible was carried out. The HGE was weighed before and after each test run to calculate the loss of weight. Because the ignition pin was completely melted, the total carbon content was introduced into the melt. Table 7 shows the amount of carbon contributed to the reduction reactions by different sources for all the experiments (in grams).

Table 7. Amount of carbon (g) contributed to the reduction reactions.

\begin{tabular}{cccccccc}
\hline Source of Carbon & Unit & Ex. 1 & Ex. 2 & Ex. 3 & Ex. 4 & Ex. 5 & Ex. 6 \\
\hline HGE & $(\mathrm{g})$ & 3.10 & 3.30 & 2.70 & 3.00 & 2.00 & 6.4 \\
Ignition pin & $(\mathrm{g})$ & 0.066 & 0.066 & 0.066 & 0.066 & 0.066 & 0.066 \\
Steel crucible & $(\mathrm{g})$ & 0.76 & 0.19 & 0.057 & 0.133 & 0.513 & 0.57 \\
\hline
\end{tabular}

The maximum amount of carbon from the HGE was contributed to the reductions observed in Ex. 6, in which the materials were continuously fed to the crucible. The melted section of the crucible differed from experiment to experiment.

\subsection{Degree of Hydrogen Utilisation $\left(\eta_{H_{2}}\right)$}

The $\eta_{\mathrm{H}_{2}}$ value was calculated by Equation (1) using the chemical composition of the off-gas and the reference diagram. The $\eta_{\mathrm{H}_{2}}$ values for the six experiments are shown in Figure 8.

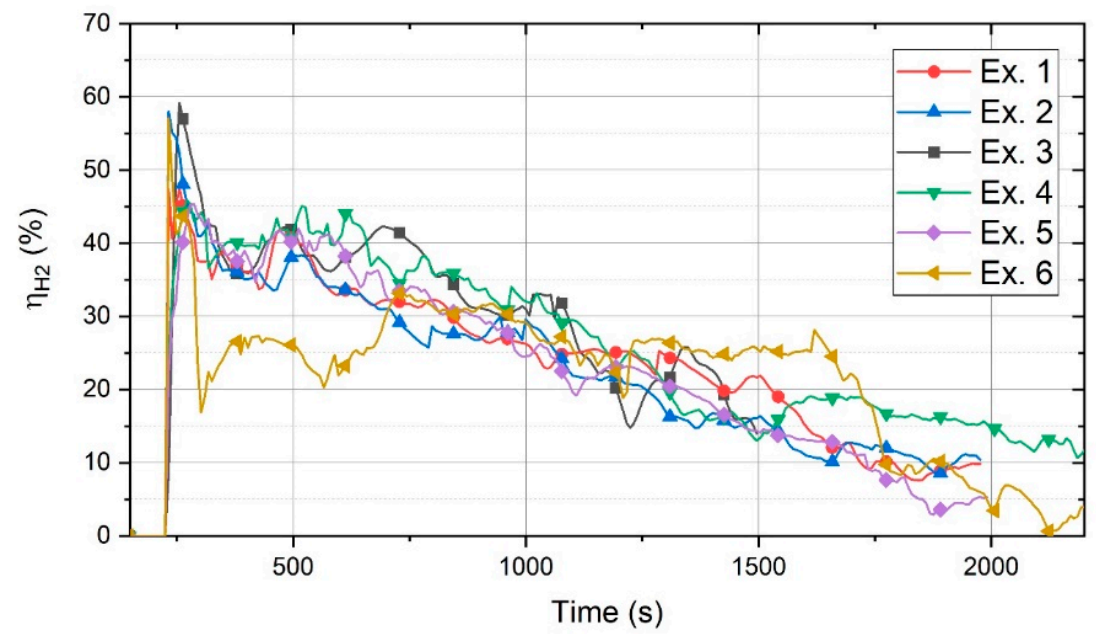

Figure 8. Degree of hydrogen utilisation $\eta_{\mathrm{H}_{2}}$

At the beginning of the reduction process (190-280 s) of Exs. 1 to $6, \eta_{\mathrm{H}_{2}}$ of all the experiments was high, and then, it decreased because a small amount of hydrogen was inside the reactor and there was a possibility of the reduction of a liquid pool of iron oxide. Therefore, a large portion of hydrogen could reduce iron oxide and form water. During the operation, iron oxide was reduced and its amount decreased, which caused a decrease in $\eta_{\mathrm{H}_{2}}$. There was no considerable difference between the $\eta_{\mathrm{H}_{2}}$ values of these experiments. However, it seems that Ex. 3 with a basicity of 2.9, the highest basicity, had the highest $\eta_{\mathrm{H}_{2}}$ value most of the time. Please note that the generation of the arc between the HGE 
and the crucible, instead of between the HGE and the iron oxide, decreased the volume of the molten iron oxide, which led to a decrease in $\eta_{\mathrm{H}_{2}}$.

Ex. 6 exhibited a different behaviour. First, as in the other experiments, $\eta_{\mathrm{H}_{2}}$ was high, and then, after $230 \mathrm{~s}$ of operation, it decreased considerably. The reason could be the transfer of the arc toward the outer surface of the steel crucible, because the bath was at the usage of $20 \mathrm{~g}$ of ore, which was too small to keep the arc in place. Therefore, a large volume of the steel crucible was empty. Thereafter, $\eta_{\mathrm{H}_{2}}$ gradually increased because of the continuous feeding of the material. During the continuous feeding, $\eta_{\mathrm{H}_{2}}$ remained approximately constant until the continuous feeding of the ore was stopped (at $1560 \mathrm{~s}$ ). After the termination of feeding, $\eta_{\mathrm{H}_{2}}$ decreased significantly.

\subsection{Degree of Reduction $\left(R_{D}\right)$}

The degree of reduction by $\mathrm{H}_{2}$ and $\mathrm{H}_{2} / \mathrm{CO}$ was studied, and the results are discussed in this section. Figure 9 shows the degree of reduction of $100 \mathrm{~g}$ of powder by hydrogen $\left(\mathrm{R}_{\mathrm{D}, \mathrm{H} 2}\right)$ for all the experiments.

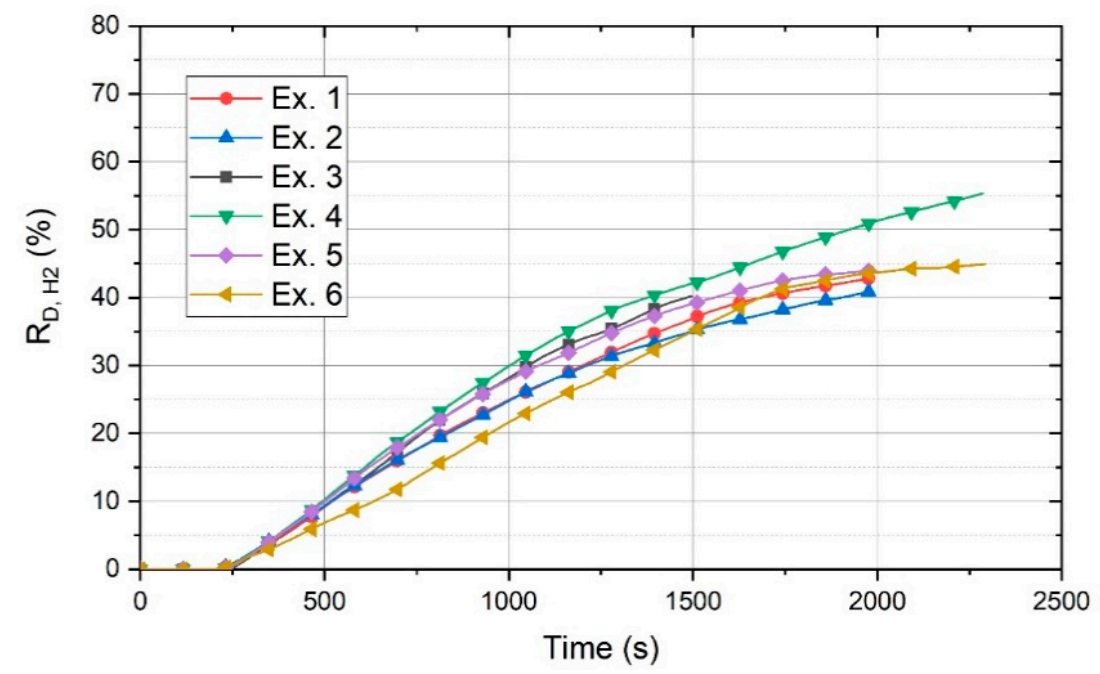

Figure 9. Degree of reduction by hydrogen $\left(\mathrm{R}_{\mathrm{D}, \mathrm{H} 2}\right)$.

The figure shows that the basicity of 2.3 is the best value to reach the highest $R_{D}$. Exs. 1 and 2 with a basicity of 0 and 0.8 , respectively, exhibited the minimum amount of $R_{D}$. However, after $1250 \mathrm{~s}$, Ex. 1 had better conditions in terms of $R_{D}$. The $R_{D}$ values of Exs. 3 and 5 with a basicity of 1.6 and 2.9, respectively, were approximately in the same range.

The $R_{D}$ value of Ex. 6, regarding $100 \mathrm{~g}$ of the charged material, was in the average range of the other experiments. In this diagram, $R_{D}$ for Ex. 6 was calculated on the basis of the total material (100 g) and not only the charged material, because for the batch-charged experiments, all of the materials were not in the liquid state during the operation. However, $R_{D}$ for Ex. 6 gradually increased to reach the values of the other experiments by the passage of the operation time. The continuous material feeding provided better conditions for the reduction processes, because, for a batch charge, the arc could be generated between the HGE and on the surface of the previously reduced section. In contrast, the continuous material feeding provided iron oxides for the reduction. The real $R_{\mathrm{D}, \mathrm{H} 2}$ and $\mathrm{R}_{\mathrm{D}, \mathrm{H} 2+\mathrm{C}}$ values of Ex. 6 in consideration of the total and only the charged material were calculated, and the corresponding graph is shown in Figure 10.

The black line shows the $\mathrm{R}_{\mathrm{D}, \mathrm{H} 2}$ value considering $100 \mathrm{~g}$ of the material. It shows that at the beginning of the reduction process, the real reduction degree was high, and then, upon the termination of continuous feeding, they became equal.

The contribution of carbon to the reduction processes is shown in Figure 11. This figure shows the total degree of reduction $\left(R_{\mathrm{D}, \mathrm{H} 2+\mathrm{C}}\right)$ of each experiment, which is the sum of the degree of reduction by carbon $\left(\mathrm{R}_{\mathrm{D}, \mathrm{C}}\right)$ and hydrogen $\left(\mathrm{R}_{\mathrm{D}, \mathrm{H} 2}\right)$. 


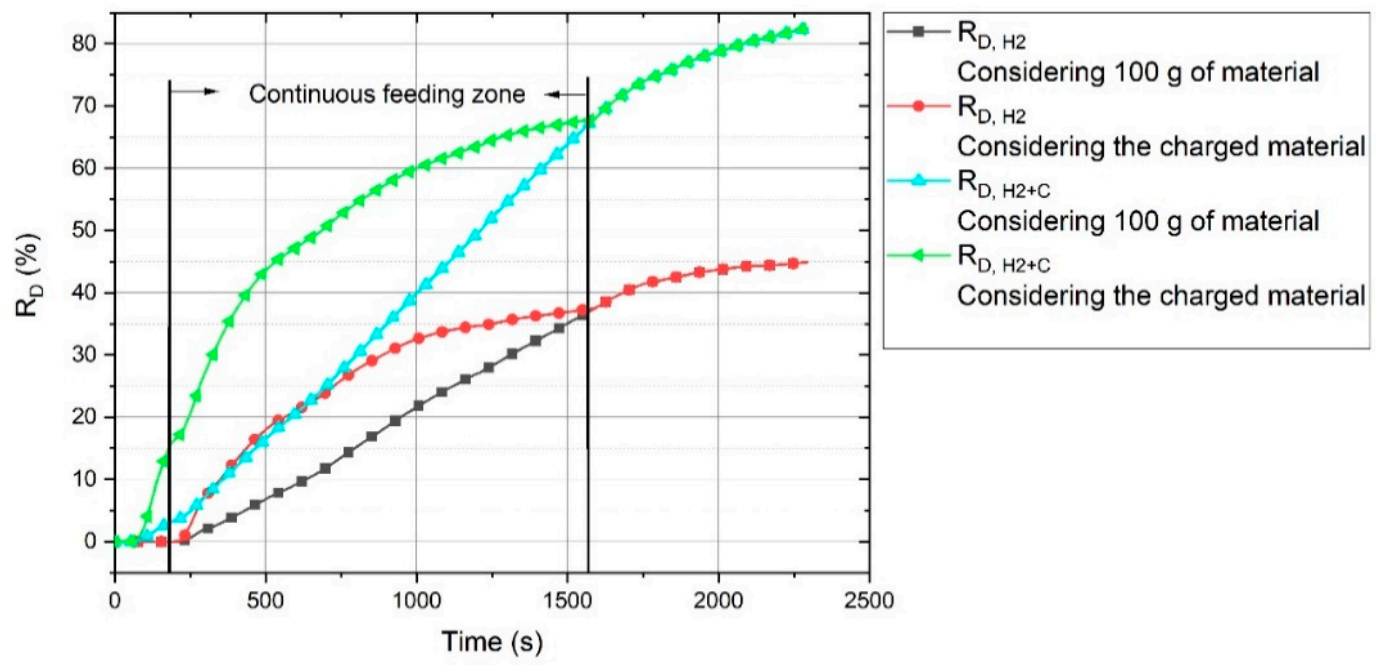

Figure 10. $\mathrm{R}_{\mathrm{D}, \mathrm{H} 2}$ regarding the total material and the charged material of Ex. 6 .

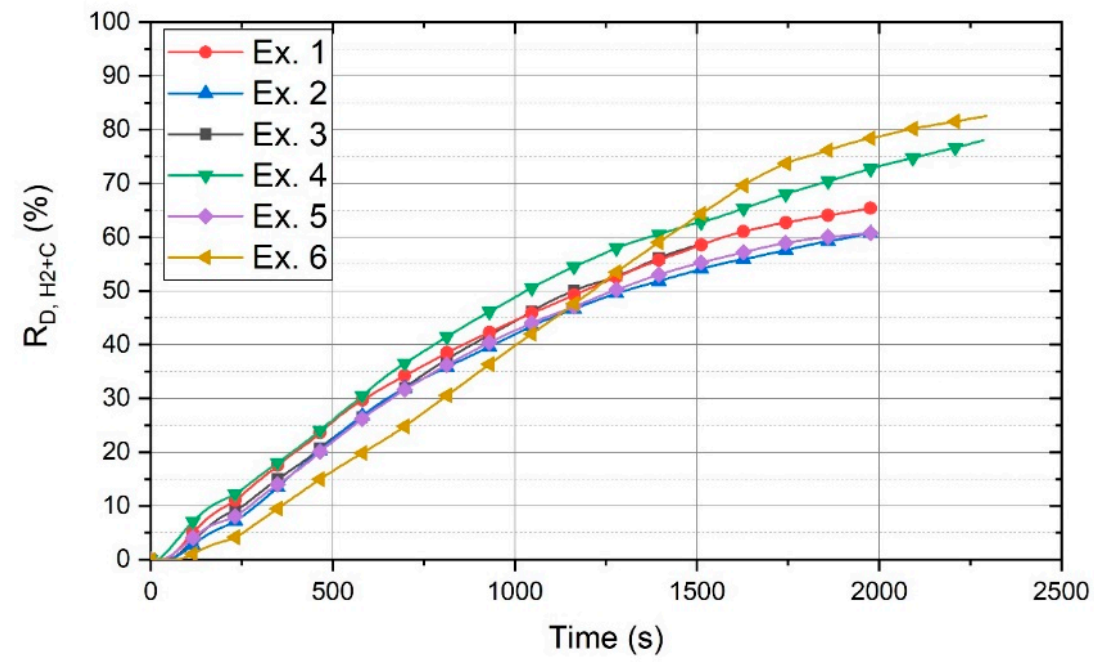

Figure 11. Total reduction degree, regarding the reduction by carbon and hydrogen.

The amount of carbon contributed to the reduction of iron oxides was approximately in the same range for the experiments with different basicities. Hence, the degree of reduction of each experiment increased uniformly. In contrast, the degree of reduction of Ex. 6 increased considerably. After $1500 \mathrm{~s}$, the total degree of reduction of Ex. 6 was greater than that of the other experiments.

To rule out the contribution of carbon to the reduction reactions, a tungsten electrode could be used instead of the HGE. Badr [15] conducted a set of experiments by using a tungsten electrode to compare the reduction rate of hematite using hydrogen thermal plasma with HGE. He subtracted the oxygen reduced by carbon from the HGE and then reported that the reduction rates of iron oxide by a tungsten electrode and the HGE were in good agreement.

\subsection{Reduction Rate}

The reduction rate of iron oxide considering only hydrogen was calculated for each experiment, and the corresponding results are shown in Figure 12.

This graph shows the rate of oxygen removed by the formation of $\mathrm{H}_{2} \mathrm{O}$. The changes and the reasons for these changes were similar to those for the graph of $\eta_{\mathrm{H}_{2}}$ (Figure 8). Here, $0.73 \mathrm{~g} / \mathrm{min}$ was the highest reduction rate, and upon the passage of time, it decreased to less than $0.2 \mathrm{~g} / \mathrm{min}$.

The reduction rate of Ex. 6 was lower than that of the other experiments in the time frame between $220 \mathrm{~s}$ and $750 \mathrm{~s}$ because of the low amount of iron oxide inside the crucible. However, the continuous 
charging of iron ore led to an increase in the reduction rate. Please note that the reduction rate was between 0.4 and $0.5 \mathrm{~g} / \mathrm{min}$ in the time range of 1250-1700 s, which was higher than that of the other experiments. This illustrated that the reduction rate could be kept constant and optimised in the case of the continuous feeding of iron ore.

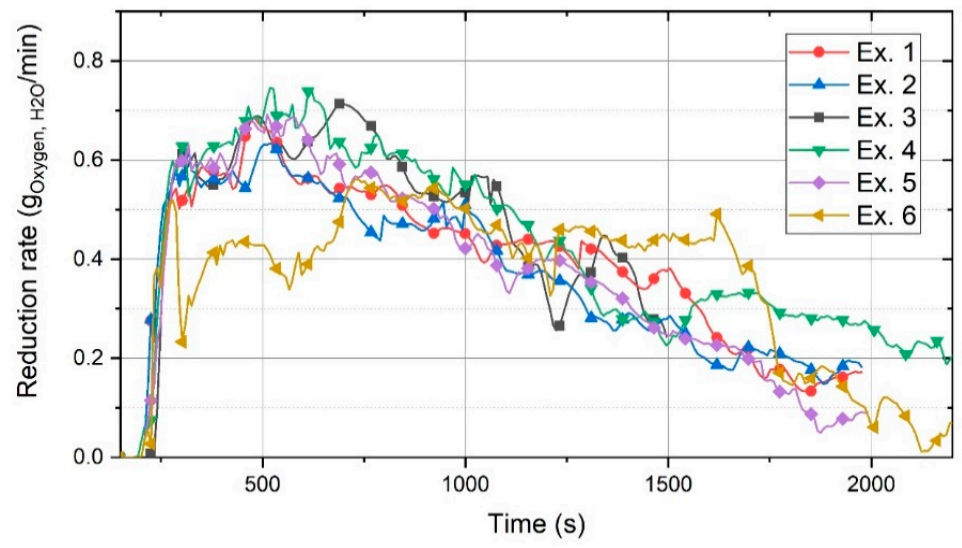

Figure 12. Reduction rate of iron oxides by hydrogen.

\subsection{Produced Iron and Slag}

The mass and energy balance were carried out to calculate the weight and the chemical composition of the slags. The chemical composition of each slag was calculated by using the $\mathrm{R}_{\mathrm{D}}$ value of each experiment and the chemical composition of the samples (mixtures of iron ore and lime) and off-gas. Table 8 shows the values of the main parameters of the products and the co-products of each experiment for the operation time of $1495 \mathrm{~s}$.

Table 8. Products and co-products of the experiments in $1495 \mathrm{~s}$ of operation.

\begin{tabular}{cccccccc}
\hline Parameter & Unit & Ex. 1 & Ex. 2 & Ex. 3 & Ex. 4 & Ex. 5 & Ex. 6 \\
\hline Produced iron & $(\mathrm{g})$ & 26.01 & 21.63 & 25.55 & 28.84 & 21.67 & 30.34 \\
$\mathrm{M}_{\mathrm{D}}$ & $(\%)$ & 39.49 & 33.41 & 40.12 & 46.03 & 35.14 & 47.64 \\
Slag weight & $(\mathrm{g})$ & 54.73 & 60.54 & 55.53 & 51.45 & 60.88 & 49.32 \\
$\mathrm{R}_{\mathrm{D}, \mathrm{H} 2}$ & $(\%)$ & 36.70 & 35.00 & 40.2 & 42.00 & 39.00 & 34.86 \\
$\mathrm{R}_{\mathrm{D}, \mathrm{C}}$ & $(\%)$ & 21.3 & 18.78 & 18.3 & 20.54 & 15.98 & 28.8 \\
$\mathrm{R}_{\mathrm{D}, \mathrm{H} 2+\mathrm{C}}$ & $(\%)$ & 58.00 & 53.78 & 58.5 & 62.54 & 54.98 & 63.66 \\
Average degree of hydrogen & $(\%)$ & 26.35 & 24.71 & 27.92 & 28.69 & 26.22 & 24.23 \\
utilisation $\left(\overline{\eta_{\mathrm{H}_{2}}}\right)$ & & & & & & &
\end{tabular}

Hematite was reduced to $\mathrm{Fe}$ and $\mathrm{FeO}$, wherein the former was considered to be the produced iron and the latter was a part of the slag. In $1495 \mathrm{~s}$, the maximum amount of metallisation, which is the ratio of the produced iron to the total iron, was $46 \mathrm{wt}$ \% for Ex. 4 with a basicity of 2.3, and the minimum metallisation belonged to Ex. 2 with a basicity of 0.8 . However, the $\mathrm{M}_{\mathrm{D}}$ value of Ex. 4 was calculated using Equation (7) as a function of $R_{D}$, whose result was 44 wt.\%. The calculation of $M_{D}$ is theoretically correct if the iron oxide inside the slag would be only $\mathrm{FeO}$ and not $\mathrm{Fe}_{2} \mathrm{O}_{3}$. However, inside the steel crucible after each test run, there was no reduced or even melted ore. Hence, there was a deviation of less than $3 \%$ between the $M_{D}$ values obtained by the two methods.

$\overline{\eta_{\mathrm{H}_{2}}}$ of Ex. 6, which was $24.23 \mathrm{wt} . \%$, was less than that of all the other experiments. Nevertheless, the metallisation was $47.64 \mathrm{wt} . \%$, which was higher than that of all the other experiments.

To assess the efficiency of the process at longer times, the operation time of some experiments was extended up to 1975 s. Table 9 shows the calculated results of the main reduction parameters. 
Table 9. Products and co-products of the experiments in $1975 \mathrm{~s}$ of operation.

\begin{tabular}{ccccccc}
\hline Parameter & Unit & Ex. 1 & Ex. 2 & Ex. 4 & Ex. 5 & Ex. 6 \\
\hline Produced iron & $(\mathrm{g})$ & 33.02 & 28.15 & 38.05 & 26.83 & 43.88 \\
$\mathrm{M}_{\mathrm{D}}$ & $(\mathrm{wt.} \%)$ & 50.14 & 43.47 & 60.73 & 43.51 & 68.91 \\
Slag weight & $(\mathrm{g})$ & 45.64 & 52.09 & 39.51 & 54.18 & 31.82 \\
$\mathrm{R}_{\mathrm{D}, \mathrm{H} 2}$ & $(\%)$ & 42.80 & 40.80 & 50.90 & 43.90 & 43.57 \\
$\mathrm{R}_{\mathrm{D}, \mathrm{C}}$ & $(\%)$ & 22.59 & 19.96 & 21.84 & 16.89 & 34.85 \\
$\mathrm{R}_{\mathrm{D}, \mathrm{H} 2+\mathrm{C}}$ & $(\%)$ & 65.39 & 60.76 & 72.74 & 60.79 & 78.42 \\
$\bar{\eta}_{\mathrm{H}_{2}}$ & $(\%)$ & 22.52 & 21.11 & 25.48 & 21.62 & 22.18 \\
\hline
\end{tabular}

The produced iron and metallisation increased by an increase in the operation time. The difference between the metallisation of Ex. 6 in $1495 \mathrm{~s}$ and $1975 \mathrm{~s}$ was considerably higher than that of the other experiments because of the continuous feeding of the iron ore to the crucible, which caused the iron oxides in the reduction zone to be reduced. This interpretation can be exemplified for a low decrease in $\overline{\eta_{\mathrm{H}_{2}}}$ for Ex. 6. This illustrated that in a continuous process of HPSR, the reduction rate can be kept constant.

$R_{\mathrm{D}, \mathrm{H} 2}$ in $1975 \mathrm{~s}$ was in every case more than $40 \%$, while $\mathrm{R}_{\mathrm{D}, \mathrm{H} 2+\mathrm{C}}$ could reach $78 \%$ with the contribution of carbon to the reduction processes. The erosion rate of HGE and the amount of $\mathrm{CO}_{2}$-emissions per ton of the produced liquid metal were presented in the previous work [33].

Figure 13 shows $R_{D, H 2}, R_{D, C}, R_{D, H 2+C}$, and $\overline{\eta_{H_{2}}}$ for an operation of $1495 \mathrm{~s}$.

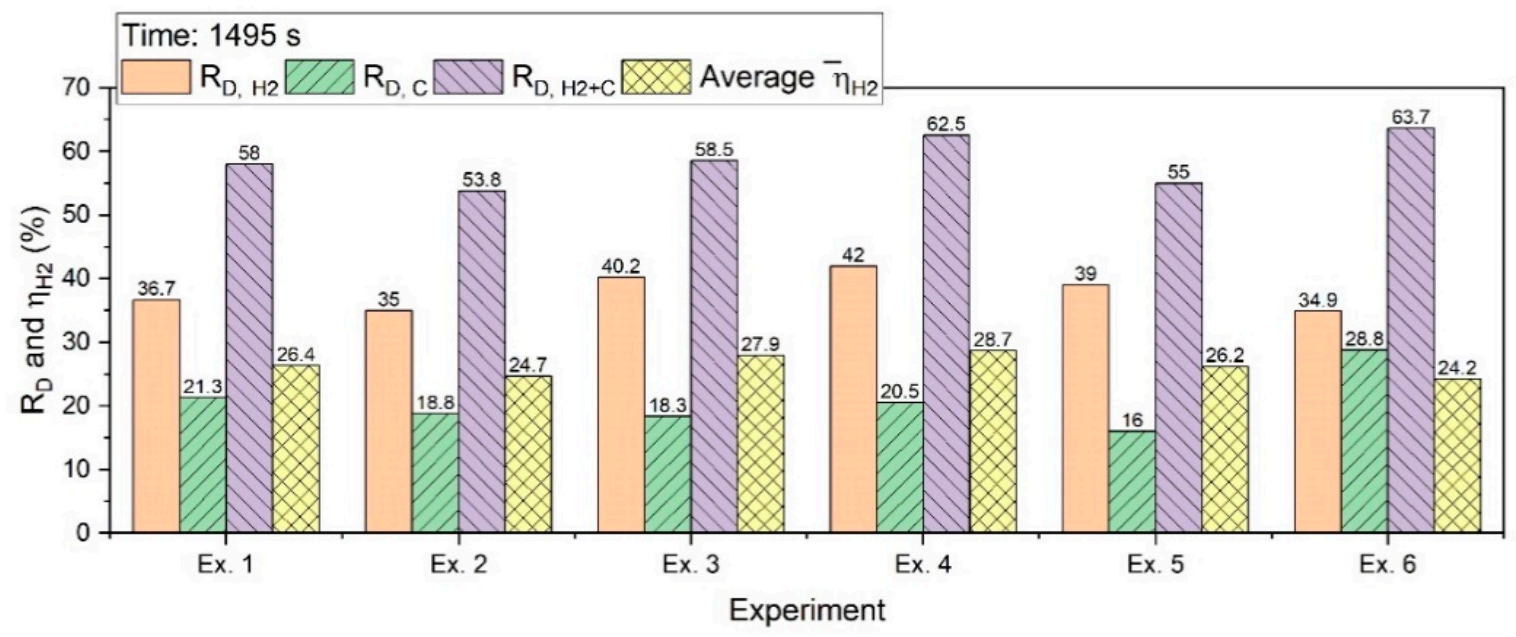

Figure 13. $\mathrm{R}_{\mathrm{D}}$ and $\overline{\eta_{\mathrm{H}_{2}}}$ in $1495 \mathrm{~s}$

$R_{D, C}$ for the batch charging experiments was in the range between $15 \%$ and $22 \%$; however, for the continuous feeding of iron ore, it was $28.8 \%$. The reasons for this have already been explained in Section 3.1. $\mathrm{R}_{\mathrm{D}, \mathrm{H} 2+\mathrm{C}}$ was between $53 \%$ and $64 \%$; Ex. 4 with a basicity of 2.3 had the highest degree among the batch experiments. A high contribution of carbon in the reduction process caused an increase in the total reduction degree for Ex. 6.

The $\overline{\eta_{\mathrm{H}_{2}}}$ value for the experiments of the batch charge in $1495 \mathrm{~s}$ was more than $25 \%$; then, with the extension of the experiments, it decreased. Figure 14 shows the $R_{D}$ value calculated in $1975 \mathrm{~s}$.

With the extension of the experiments, the degrees of reduction increased. However, the $\overline{\eta_{\mathrm{H}_{2}}}$ decreased because of a decrease in the reduction rate over the time of the operation. 


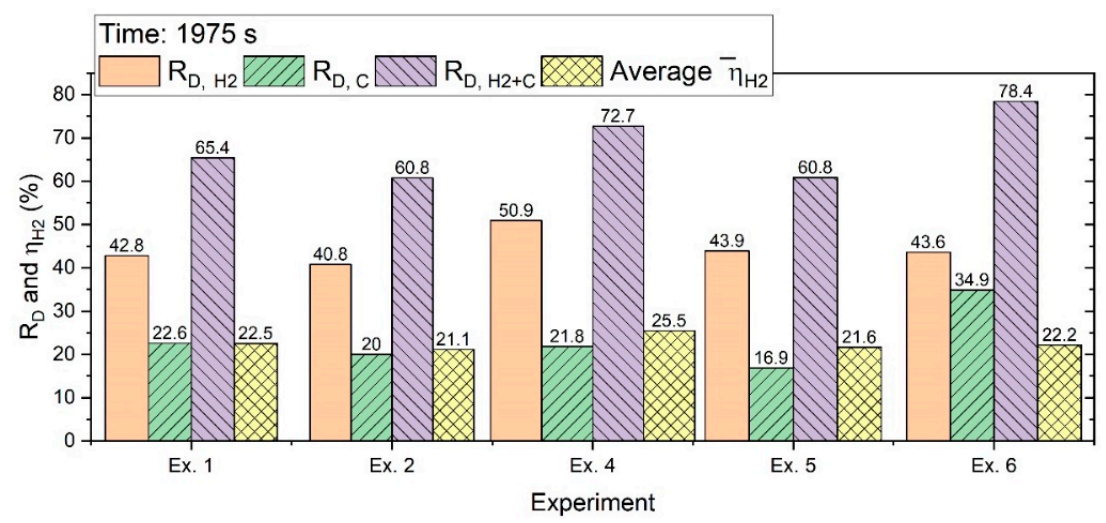

Figure 14. Degree of reduction and the average $\eta_{\mathrm{H}_{2}}$ after $1975 \mathrm{~s}$ of operation.

\subsection{Slag}

The weight of the slag for each case is mentioned in Tables 8 and 9. To calculate the chemical composition of the slag, mass and energy balance were carried out, as it was not possible by the calculations to define the amount of $\mathrm{Fe}_{2} \mathrm{O}_{3}$ and $\mathrm{FeO}$ because Fe could be present in the slag in both the forms. Therefore, the phase stability was studied by FactSage ${ }^{\mathrm{TM}} 7.2$ (Thermfact/CRCT (Montreal, Canada) at equilibrium in the same range of the reduction zone temperature. For instance, the slag composition of Ex. 5 was calculated for an operation time of $1975 \mathrm{~s}$ and is presented in Table 10.

Table 10. Calculated chemical composition of slag for Ex. 5.

\begin{tabular}{ccc}
\hline Element & Unit & Ex. 5 \\
\hline $\mathrm{CaO}$ & (wt.\%) & 10.04 \\
$\mathrm{SiO}_{2}$ & (wt.\%) & 3.444 \\
$\mathrm{Al}_{2} \mathrm{O}_{3}$ & (wt.\%) & 1.94 \\
$\mathrm{FeO}$ & (wt.\%) & 80.62 \\
$\mathrm{MgO}$ & (wt.\%) & 0.14 \\
$\mathrm{Fe}_{2} \mathrm{O}_{3}$ & (wt.\%) & 3.21 \\
$\mathrm{~K}_{2} \mathrm{O}$ & (wt.\%) & 0.03 \\
$\mathrm{MnO}$ & (wt.\%) & 0.34 \\
$\mathrm{P}$ & (wt.\%) & 0.22 \\
$\mathrm{~S}$ & (wt.\%) & 0.01 \\
\hline
\end{tabular}

The composition and the morphology of the slags of Exs. 5 and 6 were studied by SEM. At the end of the experiments, a layer of slag covered the produced iron, and the morphology and the chemical compositions of both sides were studied. Figure 15 shows the morphology and the locations of the spectra on the upper side of the slag layer of Ex. 5.

It mainly consisted of white balls, which are iron ore particles, in a matrix of slag. The distribution of the ore particles was not uniform.

Furthermore, the lower side of the slag layer was assessed in terms of its morphology and chemical composition. Figure 16 shows the microstructure of the lower side of the slag with the locations of the spectra.

On the lower side of the slag, the iron oxide particles were not observed. This means that iron oxide particles were melted and mixed with slag before reaching the lower side of the slag.

Figure 17 shows a section of slag of Ex. 6 with some droplets of the produced iron.

It shows that the iron oxide particles during continuous feeding were reduced and formed iron droplets in a matrix of slag. The droplets were grown to be heavier to leave the slag layer to penetrate into the melt.

The composition of the slags was measured at different locations by means of EDX, and the corresponding results are presented in Table 11. 


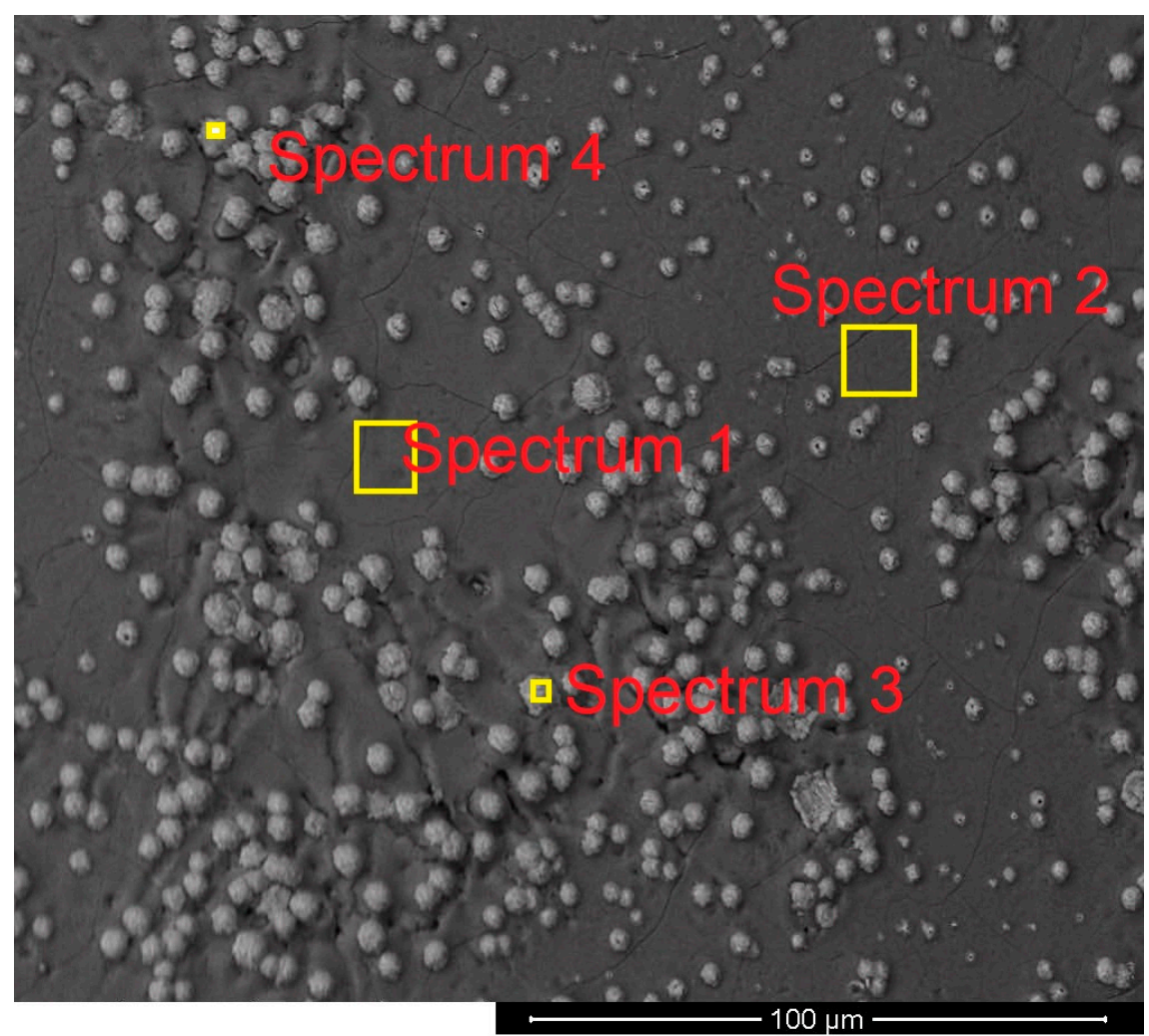

Figure 15. Morphology and the locations of spectra on the upper side of the slag layer of Ex. 5.

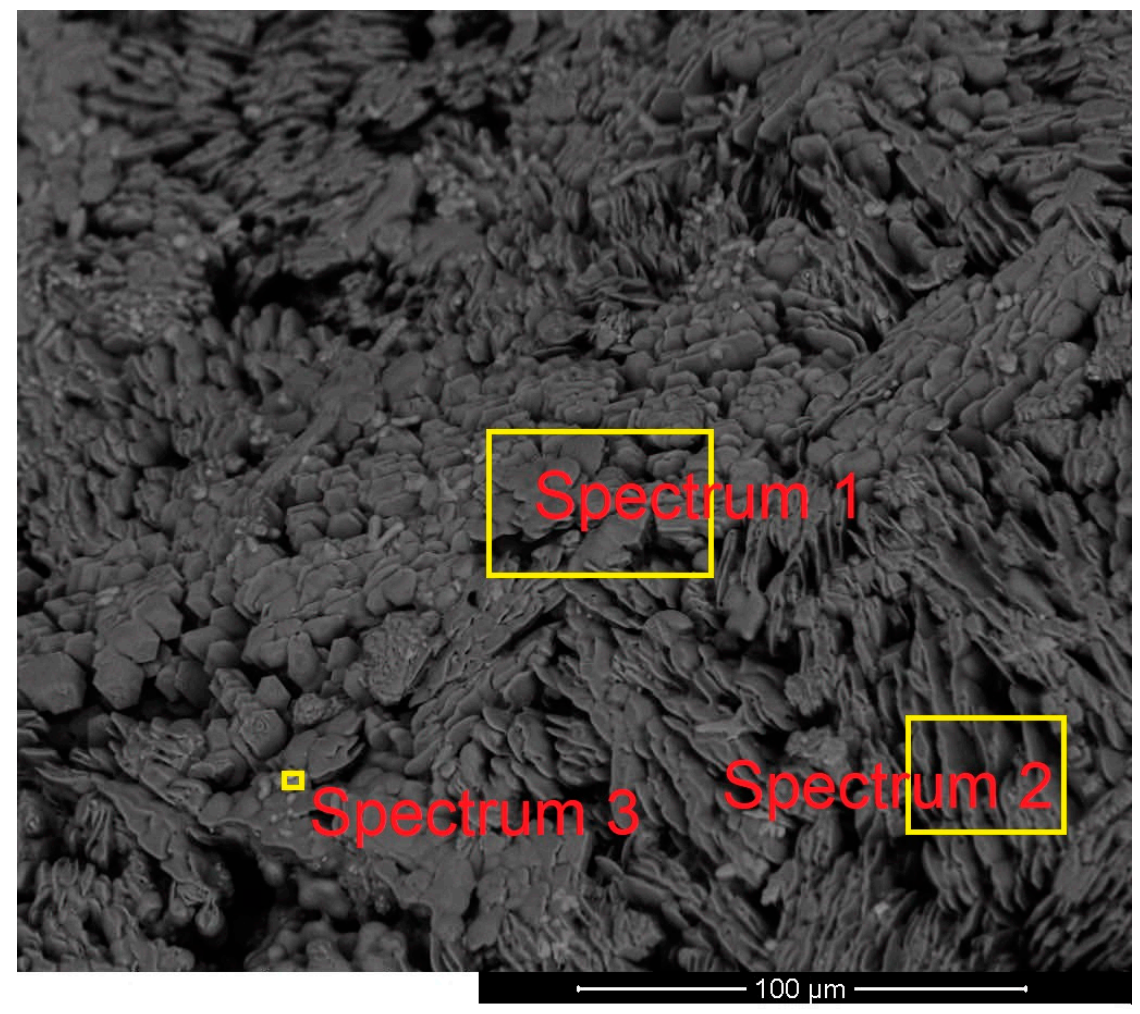

Figure 16. Morphology and the locations of spectra on the lower side of the slag layer of Ex. 5. 


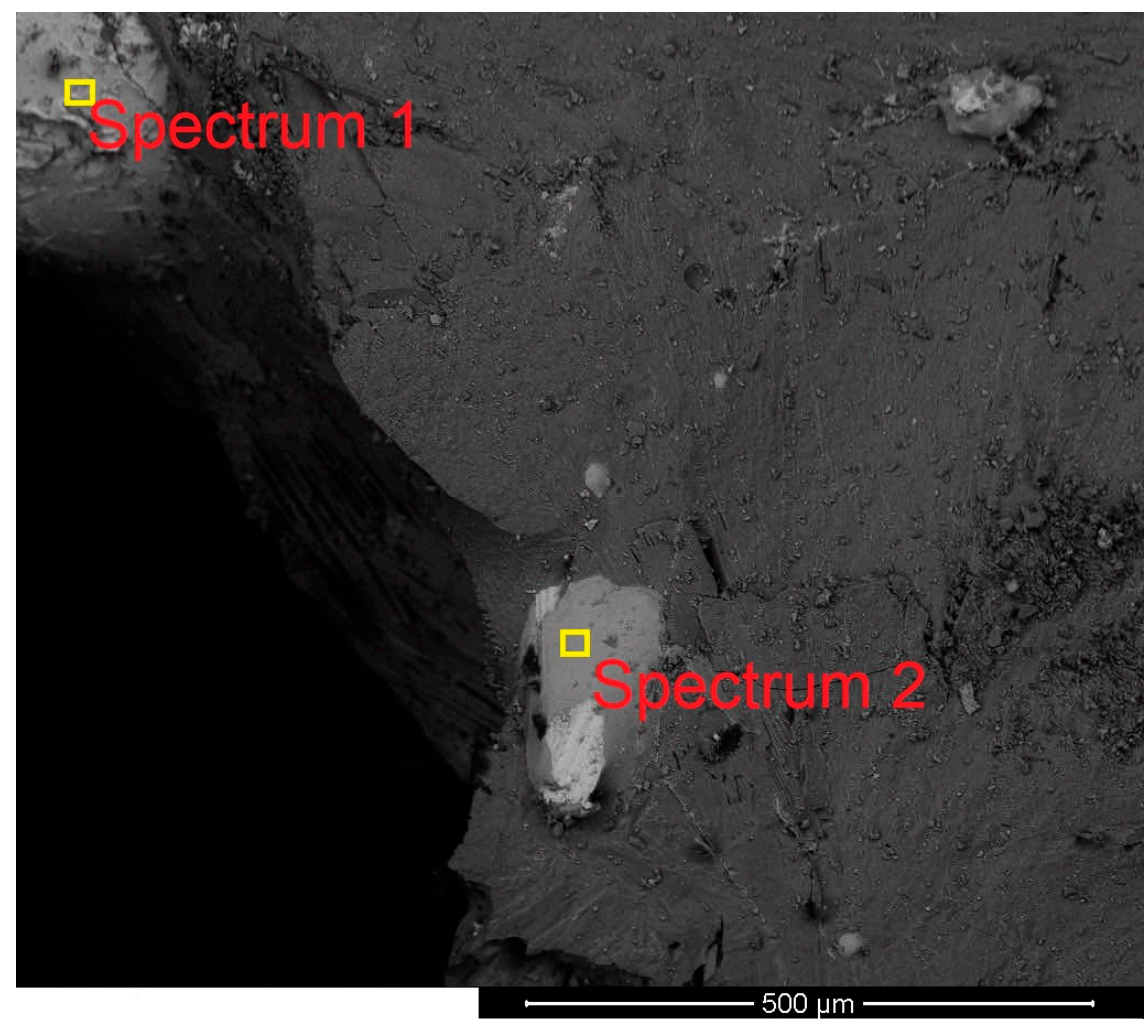

Figure 17. Section of slag with some droplets of produced iron for Ex. 6 .

Table 11. Composition of the slag measured by EDX.

\begin{tabular}{ccccccccccc}
\hline Parameter & Spectrum & Figure & Unit & $\mathbf{O}$ & $\mathbf{M g}$ & Al & Si & Ca & Mn & Fe \\
\hline Slag composition & 1 and 2 & 15 & $($ wt.\%) & 41.5 & 1.3 & 0.4 & 16.0 & 35.2 & 2.6 & 3.0 \\
$\quad \begin{array}{c}\text { Iron oxide } \\
\text { particles }\end{array}$ & 3 and 4 & 15 & $($ wt.\%) & 35.5 & 0.8 & 0.3 & 4.3 & 9.5 & 1.3 & 48.3 \\
$\begin{array}{c}\text { Slag composition } \\
\begin{array}{c}\text { Droplets of } \\
\text { produced iron }\end{array}\end{array}$ & 1,2 and 3 & 16 & (wt.\%) & 37.5 & 4.4 & 0.9 & 15.3 & 36.3 & 4.8 & 0.8 \\
\hline
\end{tabular}

Spectra 1 and 2 of Figure 15 and 1, 2, and 3 of Figure 16 show a difference between the composition of the lower side and the upper side. On the lower side, the amount of iron oxides was less than that of the upper side because of the reduction process. The amounts of $\mathrm{Mg}$ and $\mathrm{Mn}$ on the lower side were higher than those of the other side. To check the results of EDX, a sample of slag from Ex. 5 was analysed by using X-ray fluorescence (XRF), and the corresponding results are shown in Table 12.

Table 12. Chemical composition of Ex. 5 slag by means of XRF.

\begin{tabular}{ccc}
\hline Elements & Unit & Ex. 5 \\
\hline $\mathrm{CaO}$ & $($ wt.\%) & 36.64 \\
$\mathrm{SiO}_{2}$ & $($ wt.\%) & 22.88 \\
$\mathrm{Al}_{2} \mathrm{O}_{3}$ & $($ wt.\%) & 9.51 \\
$\mathrm{FeO}$ & $($ wt.\%) & 6.34 \\
$\mathrm{MgO}$ & $($ wt.\%) & 14.88 \\
$\mathrm{MnO}$ & $($ wt.\%) & 7.85 \\
$\mathrm{TiO}_{2}$ & $($ wt.\%) & 0.32 \\
$\mathrm{Cr}_{2} \mathrm{O}_{3}$ & $($ wt.\%) & 0.26 \\
$\mathrm{ZrO}_{2}$ & $($ wt.\%) & 1.17 \\
$\mathrm{P}_{2} \mathrm{O}_{5}$ & (wt.\%) & 0.13 \\
\hline
\end{tabular}


Nevertheless, Fe could exist in the form of $\mathrm{Fe}^{2+}$ or $\mathrm{Fe}^{3+}$ in the slag; this is mentioned in the table as $\mathrm{Fe}^{2+}$ because by XRF, it was not possible to define the amounts of $\mathrm{Fe}^{2+}$ and $\mathrm{Fe}^{3+}$.

There was a large difference between the calculated chemical composition of the slag (Table 10) and the results of XRF (Table 12). The real composition of the slag showed that the basicity of the slag was lower than that expected. The basicity should have been 2.9 ; however, it was 1.6 according to Table 12. The main reason was the entry of the material from the refractory to the melt. Sodium silicate was used as a binder for the application of the refractory lining. Therefore, the melting of the refractory material and mixing with slags increased the amount of $\mathrm{SiO}_{2}$, which was why the real basicity was lower. The other point for the deviation of the real composition of the slag was the high reduction degree of iron oxide. Because slag was not homogenised, the iron oxide particles exposed to the reduction agent and plasma arc were reduced and the rest buried by the partially melted material in the steel crucible could not be reduced. This led to the production of a non-homogenised slag in the crucible. Therefore, to achieve the best conditions for the reduction process, the material inside the crucible should be completely melted. However, in the laboratory-scale facility, it was not possible to keep the material in the liquid phase during the operation, because of the use of a low-power furnace and cooling the system with water. Therefore, the achievement of a high degree of reduction was not possible with the laboratory-scale facility. Figure 18 shows the slag or iron oxide buried by the produced iron.

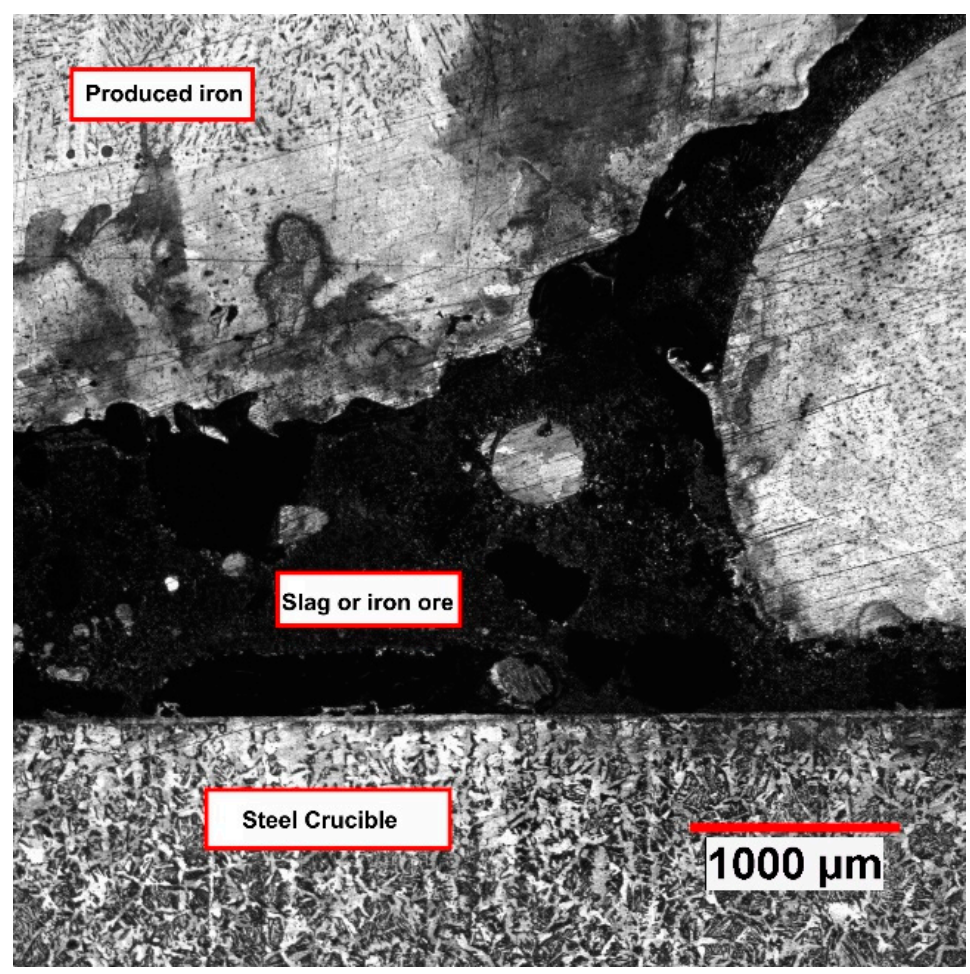

Figure 18. A cross-section of the crucible, unmelted crucible, a layer of slag or iron ore under a layer of produced iron, Ex. 2.

The figure shows a mass of slag or non-reduced iron oxide buried under a layer of produced iron. Therefore, even with the extension of the operation time, the chance of reducing this section of material was low.

The composition of the slag in Table 12 shows that the FeO content in the slag was less than $7 \%$. This means that it was feasible to achieve a high degree of reduction in this process if the material could be melted and contacted with the reducing agent.

According to the composition of iron ore and lime, it was expected to produce a slag with a higher content of $\mathrm{Al}_{2} \mathrm{O}_{3}$ than that of $\mathrm{MgO}$. However, due to the introduction of $\mathrm{MgO}$ from the refractory lining, 
the amount of $\mathrm{MgO}$ in the slag was higher than that of $\mathrm{Al}_{2} \mathrm{O}_{3}$. To analyse the liquidus temperature of the slag, two ternary systems, $\mathrm{SiO}_{2}-\mathrm{FeO}-\mathrm{Al}_{2} \mathrm{O}_{3}$ and $\mathrm{SiO}_{2}-\mathrm{FeO}-\mathrm{MgO}$, with the additions of $\mathrm{CaO}$ were studied using FactSage ${ }^{\mathrm{TM}}$ 7.2. The maximum calculated basicity was 2.9 for Ex. 5; however, the chemical composition of the slag showed that it decreased to 1.6 due to the mixing of the refractory lining material with the melt. During the reduction process, the $\mathrm{CaO}$ amount in the slag continuously increased due to the decrease in the iron oxide.

A set of calculations was carried out to assess the possible solidifications of the $\mathrm{SiO}_{2}-\mathrm{FeO}-\mathrm{Al}_{2} \mathrm{O}_{3}$ system for the slags with $0 \%$ and $37 \%$ of $\mathrm{CaO}$ at $1550{ }^{\circ} \mathrm{C}$. The results are shown in Figure 19.

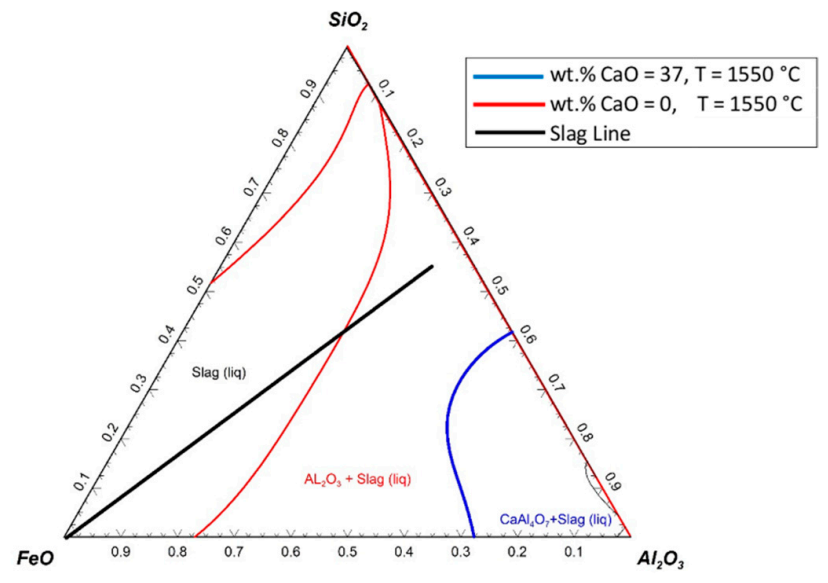

Figure 19. Ternary system of $\mathrm{SiO}_{2}-\mathrm{FeO}-\mathrm{Al}_{2} \mathrm{O}_{3}$ with various addition of $0 \%$ and $37 \mathrm{wt} . \% \mathrm{CaO}$ at $1550{ }^{\circ} \mathrm{C}$.

The presumptive slag line shows the changes in the slag composition during the reduction process. Nevertheless, the slag line was assumed to be a straight line; it could have different paths according to the melting and the reduction process. At the beginning of the reduction process, the FeO content in the slag was high, and then, because of the reduction process, it decreased. The red line shows the liquidus temperature of the slag without any addition of $\mathrm{CaO}$. The solid particles could be formed if the $\mathrm{FeO}$ content decreased to less than $30 \%$. The blue line shows the liquidus temperature of the slag with $37 \mathrm{wt}$ \% $\mathrm{CaO}$; therefore, the graph was normalised to $100 \%$ for the other components of the slag $\left(\mathrm{SiO}_{2}-\mathrm{FeO}-\mathrm{Al}_{2} \mathrm{O}_{3}\right)$. The slag line did not cross the line of the chart where $37 \mathrm{wt} . \%$ of $\mathrm{CaO}$ was added to the slag at $1550{ }^{\circ} \mathrm{C}$; the slag always stayed in the liquid state. Hence, the reduction rate could be improved.

The ternary system of $\mathrm{SiO}_{2}-\mathrm{FeO}-\mathrm{MgO}$ with an addition of $37 \mathrm{wt}$ \% $\mathrm{CaO}$ is shown in Figure 20.

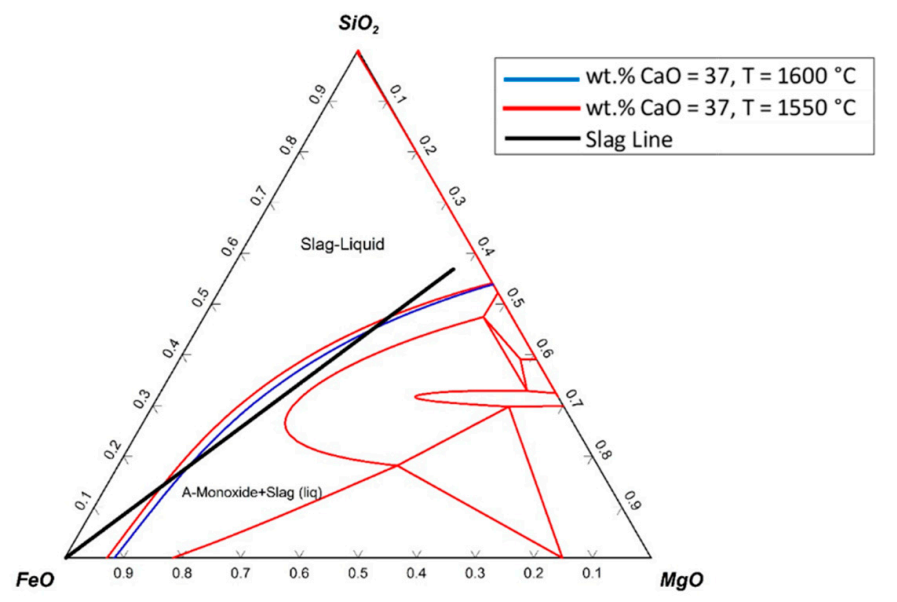

Figure 20. Ternary system of $\mathrm{SiO}_{2}-\mathrm{FeO}-\mathrm{MgO}$ with addition of $37 \mathrm{wt} . \% \mathrm{CaO}$ at $1550{ }^{\circ} \mathrm{C}$ and $1600{ }^{\circ} \mathrm{C}$. 
The ternary phase diagram was drawn at $1550{ }^{\circ} \mathrm{C}$, and only one line (blue line) was added to the diagram, which was the liquidus line of the diagram at $1600{ }^{\circ} \mathrm{C}$. The slag line crossed the liquidus line, which implied that during the reduction process, solid particles existed in the slag. Therefore, to melt the slag completely, the temperature had to be increased.

Furthermore, the $\mathrm{SiO}_{2}-\mathrm{FeO}-\mathrm{MgO}$ system with no addition of $\mathrm{CaO}$ is shown in Figure 21.

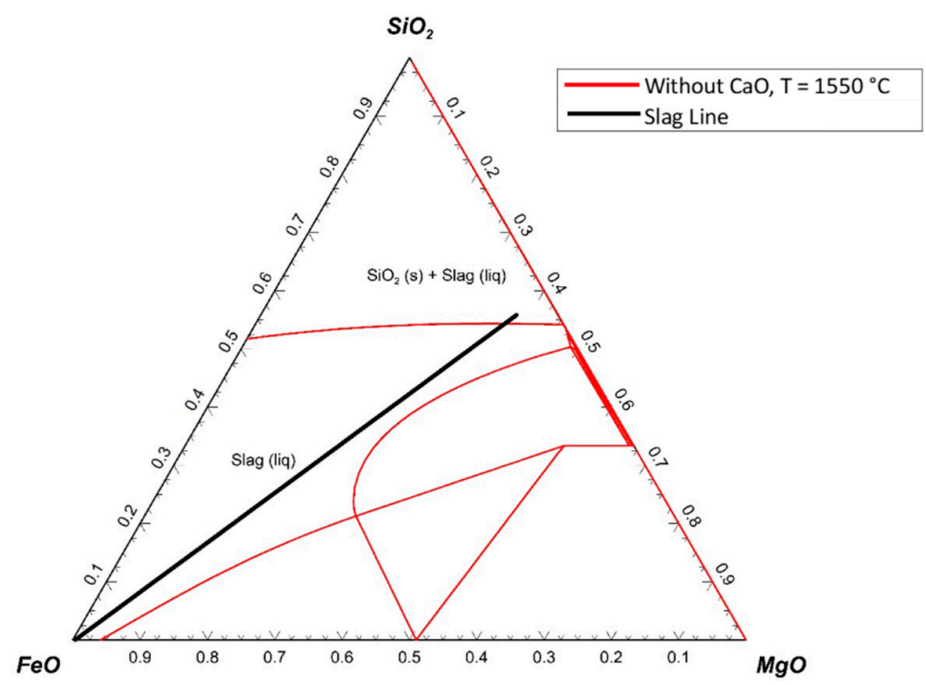

Figure 21. Ternary system of $\mathrm{SiO}_{2}-\mathrm{FeO}-\mathrm{MgO}$ with no addition of $\mathrm{CaO}$ at $1550{ }^{\circ} \mathrm{C}$.

In this system, the slag line was located in the liquid slag. However, with a decrease in the FeO content to less than below $10 \%$, the solid particles of $\mathrm{SiO}_{2}$ might be formed.

With a comparison of these three ternary diagrams, it can be suggested that the $\mathrm{SiO}_{2}-\mathrm{FeO}-\mathrm{Al}_{2} \mathrm{O}_{3}$ system with the addition of $\mathrm{CaO}$ was appropriate for the operations, as in this system, there was no solid component in the slag phase at $1550{ }^{\circ} \mathrm{C}$. Furthermore, preventing the entrance of refractory materials to the melt can improve the reduction process. One solution is the use of high-alumina refractories such as spinel- instead of magnesia-based refractories.

\section{Conclusions}

Hydrogen can be considered to be a reducing agent for the reduction of iron oxides using the hydrogen plasma smelting reduction process. The main conclusions of the present study are as follows:

- HPSR produces a small amount of $\mathrm{CO}_{2}$ due to the contribution of carbon, from graphite electrode, to the reduction reactions. $\mathrm{CO}_{2}$ emissions were much lower than those of other iron and steel-making routes.

- $\eta_{\mathrm{H}_{2}}$ was high at the beginning of the reduction process, and then, it decreased due to a decrease in the iron oxide content in the liquid slag.

- During the continuous feeding process of iron ore, the $\eta_{\mathrm{H}_{2}}$ value could be kept constant. Therefore, we expect to achieve a high $\eta_{\mathrm{H}_{2}}$ value in an industrial scale of this process.

- The average $\eta_{\mathrm{H}_{2}}$ value was approximately $28 \%$ for the samples with a basicity of 1.6 and 2.3 .

- Iron oxide, buried by the partially melted material in the steel crucible, could not be reduced. Therefore, the achievement of a high $\mathrm{R}_{\mathrm{D}}$ value was not possible in the laboratory-scale facility.

- The chemical composition of the slags showed that the FeO content was low; therefore, it seems to be possible to achieve higher degrees of reduction if all the material in the reactor is melted.

Author Contributions: Conceptualisation, M.N.S. and J.S.; methodology, M.N.S.; software, M.N.S.; project administration, M.N.S., J.S., and D.S.; validation, M.N.S. and J.S.; formal analysis, M.N.S.; investigation, M.N.S.; resources, M.N.S.; writing (original draft preparation), M.N.S.; review and editing, M.N.S., J.S., D.S., and M.A.Z.; 
visualisation, M.N.S., J.S. D.S., and M.A.Z.; supervision, M.N.S. and J.S. All authors have read and agreed to the published version of the manuscript.

Funding: The SuSteel Project supported this research. The SuSteel project was funded by the Austrian Research Promotion Agency (FFG). Montanuniversitaet Leoben, K1-Met GmbH, voestalpine Stahl Donawitz GmbH, and voestalpine Stahl Linz $\mathrm{GmbH}$ are the partners of the SuSteel project.

Acknowledgments: We are thankful to our colleagues Lukas Demmerer for technical support and Ing. Bernd Lederhaas for obtaining the SEM images.

Conflicts of Interest: The authors declare no conflict of interest.

\section{References}

1. Victor, D.G.; Ahmed, E.H.M.; Dadhich, P.K.; Olivier, J.G.J.; Rogner, H.H.; Sheikho, K.; Yamaguchi, M. Climate Change 2014: Mitigation of Climate Change; Contribution of Working Group III to the Fifth Assessment Report of the Intergovernmental Panel on Climate Change: Introductory Chapter; Cambridge University Press: Cambridge, UK; New York, NY, USA, 2014.

2. Fischedick, M.; Roy, J.; Abdel-Aziz, A.; Acquaye, A.; Allwood, J.M. Climate Change 2014: Mitigation of Climate Change; Contribution of Working Group III to the Fifth Assessment Report of the Intergovernmental Panel on Climate Change: Chapter 10; Cambridge University Press: Cambridge, UK; New York, NY, USA, 2014.

3. Seits information for decision-making. Energy Efficiency and $\mathrm{CO}_{2}$ Energy efficiency and $\mathrm{CO}_{2}$ reduction in the iron and steel industry. Available online: https://setis.ec.europa.eu/system/files/Technology Information_Sheet_Energy_Efficiency_and_CO2_Reduction_in_the_Iron_and_Steel_Industry.pdf (accessed on 19 February 2019).

4. Fact Sheet: Steel and Raw Materials. Available online: https://www.worldsteel.org/en/dam/jcr:16ad9bcddbf5-449f-b42c-b220952767bf/fact_raw\%2520materials_2019.pdf (accessed on 19 February 2019).

5. Lisienko, V.G.; Lapteva, A.V.; Chesnokov, Y.N.; Lugovkin, V.V. Greenhouse-gas $\left(\mathrm{CO}_{2}\right)$ emissions in the steel industry. Steel Transl. 2015, 45, 623-626. [CrossRef]

6. Basson, E. World Steel in Figures 2017. Available online: https://www.worldsteel.org/en/dam/jcr:0474d2089108-4927-ace8-4ac5445c5df8/World+Steel+in+Figures+2017.pdf (accessed on 2 May 2018).

7. Schenk, J.; Lügen, H.B. Potenziale der Direkt- und Schmelzreduktionsverfahren für eine effiziente Anwendung in Europa. Stahl Eisen 2016, 136, 41-47.

8. Badr, K.; Bäck, E.; Krieger, W. Reduction of Iron Ore by a Mixture of Ar-H2 with $\mathrm{CO}$ and $\mathrm{CO}_{2}$ Under Plasma Application; Kyoto University: Kyoto, Japan, 2007.

9. Kirschen, M.; Badr, K.; Pfeifer, H. Influence of direct reduced iron on the energy balance of the electric arc furnace in steel industry. Energy 2011, 36, 6146-6155. [CrossRef]

10. Saumon, C. Fluid hydrogen at high density: The plasma phase transition. Phys. Rev. Lett. 1989, 62, $2397-2400$. [CrossRef] [PubMed]

11. Van Horn, H.M. Dense Astrophysical Plasmas. Science 1991, 252, 384-389. [CrossRef] [PubMed]

12. Dissociation and Ionization of Warm Dense Hydrogen. Available online: http://www.wag.caltech.edu/home/ jsu/Thesis/node31.html (accessed on 28 January 2016).

13. Naseri Seftejani, M.; Schenk, J. Thermodynamic of Liquid Iron Ore Reduction by Hydrogen Thermal Plasma. Metals 2018, 8, 1051. [CrossRef]

14. Purification Process and Characterization of Ultra High Purity Metals; Springer: Berlin, Germany, 2013; ISBN 978-3-642-62530-5.

15. Badr, K. Smelting of Iron Oxides Using Hydrogen Based Plasmas. Ph.D. Thesis, Montanuniversitaet Leoben, Leoben, Austria, 2007.

16. Brecelj, F.; Mozetic, M. Reduction of metal oxide thin layers by hydrogen plasma. Vacuum 1990, 40, $177-181$. [CrossRef]

17. Bullard, D.E.; Lynch, D.C. Reduction of titanium dioxide in a nonequilibrium hydrogen plasma. Metall. Mater. Trans. B 1997, 28, 1069-1080. [CrossRef]

18. Dayal, A.R.; Sadedin, D.R. Application of pulsed traveling hydrogen arcs for metal oxide reduction. Plasma Chem. Plasma Process. 2003, 23, 627-649. [CrossRef]

19. Major, S.; Kumar, S.; Bhatnag, M.; Chopra, K.L. Effect of hydrogen plasma treatment on transparent conducting oxides. Appl. Phys. Lett. 1986, 49, 394-396. [CrossRef] 
20. Sabat, K.C.; Paramguru, R.K.; Pradhan, S.; Mishra, B.K. Reduction of cobalt oxide $\left(\mathrm{Co}_{3} \mathrm{O}_{4}\right)$ by low temperature hydrogen plasma. Plasma Chem. Plasma Process. 2015, 35, 387-399. [CrossRef]

21. Weigel, A.; Lemperle, M.; Lyhs, W.; Wilhelmi, H. Experiments on the reduction of iron ores with an argon hydrogen plasma. In Proceedings of the ISPC-7, Eindhoven, The Netherlands, 1-5 July 1985; pp. 1214-1219.

22. Gold, R.G.; Sandall, W.R.; Cheplick, P.G.; MacRae, D.R. Plasma reduction of iron oxide with hydrogen and natural gas at $100 \mathrm{~kW}$ and $1 \mathrm{MW}$. Ironmak. Steelmak. 1977, 4, 10-14.

23. Gilles, H.L.; Clump, C.W. Reduction of iron ore with hydrogen in a direct current plasma jet. Ind. Eng. Chem. Proc. Des. Dev. 1970, 9, 194-207. [CrossRef]

24. Hiebler, H.; Plaul, J.F. Hydrogen plasma- smelting reduction- an option for steel making in the future. METABK 2004, 43, 155-162.

25. Plaul, J.F. Schmelzreduktion von hämatitischen Feinerzen im Wasserstoff-Argon-Plasma. Ph.D. Thesis, Montanuniversitaet Leoben, Leoben, Austria, 2005.

26. Sormann, A. Untersuchungen zur Schmelzreduktion von Eisenoxiden mit Wasserstoff als Reduktionsmittel. Ph.D. Thesis, Montanuniversitaet Leoben, Leoben, Austria, 1992.

27. Bäck, E. Schmelzreduktion von Eisenoxiden mit Argon-Wasserstoff-Plasma. Ph.D. Thesis, Montanuniversitaet Leoben, Leoben, Austria, 1998.

28. Kamiya, K.; Kitahara, N.; Morinaka, I.; Sakuraya, K.; Ozawa, M.; Tanaka, M. Reduction of molten iron oxide and $\mathrm{FeO}$ bearing slags by H2-Ar plasma. ISIJ Int. 1984, 24, 7-16. [CrossRef]

29. Nakamura, Y.; Ito, M.; Ishikawa, H. Reduction and dephosphorization of molten iron-oxide with hydrogen-argon plasma. Tetsu-to-Hagane 1980, 66, 2100-2105. [CrossRef]

30. Kitamura, T.; Shibata, K.; Takeda, K. In-flight reduction of $\mathrm{Fe}_{2} \mathrm{O}_{3}, \mathrm{Cr}_{2} \mathrm{O}_{3}, \mathrm{TiO}_{2}$ and $\mathrm{Al}_{2} \mathrm{O}_{3}$ by $\mathrm{Ar}-\mathrm{H}_{2}$ and Ar-CH4 plasma. ISIJ Int. 1993, 33, 1150-1158. [CrossRef]

31. Nagasaka, T.; Hino, M.; Ban-ya, S. Interfacial kinetics of hydrogen with liquid slag containing iron oxide. Metall. Mater. Trans. B 2000, 31, 945-955. [CrossRef]

32. Nagasaka, T.; Iguchi, Y.; Ban-Ya, S. Effect of additives on the rate of reduction of liquid iron oxide with CO. Tetsu-to-Hagane 1989, 75, 74-81. [CrossRef]

33. Naseri Seftejani, M.; Schenk, J.; Zarl, M.A. Reduction of Haematite Using Hydrogen Thermal Plasma. Materials 2019, 12, 1608. [CrossRef] [PubMed]

(C) 2020 by the authors. Licensee MDPI, Basel, Switzerland. This article is an open access article distributed under the terms and conditions of the Creative Commons Attribution (CC BY) license (http://creativecommons.org/licenses/by/4.0/). 